GA-A22516

\title{
EFFECTS OF EXB VELOCITY SHEAR AND MAGNETIC SHEAR ON TURBULENCE AND TRANSPORT IN MAGNETIC CONFINEMENT DEVICES
}

by
K.H. BURRELL

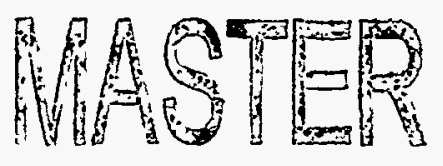

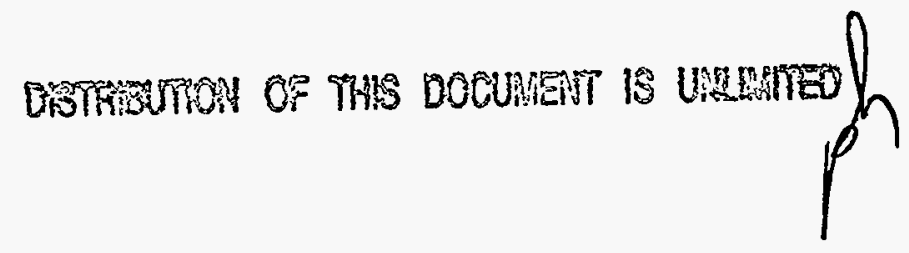

RECEIVED APR 181997

OSTI

NOVEMBER 1996 


\section{DISCLAIMER}

This report was prepared as an account of work sponsored by an agency of the United States Government. Neither the United States Government nor any agency thereof, nor any of their employees, make any warranty, express or implied, or assumes any legal liability or responsibility for the accuracy, completeness, or usefulness of any information, apparatus, product, or process disclosed, or represents that its use would not infringe privately owned rights. Reference herein to any specific commercial product, process, or service by trade name, trademark, manufacturer, or otherwise does not necessarily constitute or imply its endorsement, recommendation, or favoring by the United States Government or any agency thereof. The views and opinions of authors expressed herein do not necessarily state or reflect those of the United States Government or any agency thereof. 


\section{DISCLAMMER}

Portions of this document may be illegible in electronic image products. Images are produced from the best available original document. 


\section{DISCLAIMER}

This report was prepared as an account of work sponsored by an agency of the United States Government. Neither the United States Government nor any agency thereof, nor any of their employees, makes any warranty, express or implied, or assumes any legal liability or responsibility for the accuracy, completeness, or usefulness of any information, apparatus, produce, or process disclosed, or represents that its use would not infringe privately owned rights. Reference herein to any specific commercial product, process, or service by trade name, trademark, manufacturer, or otherwise, does not necessarily constitute or imply its endorsement, recommendation, or favoring by the United States Government or any agency thereof. The views and opinions of authors expressed herein do not necessarily state or reflect those of the United States Government or any agency thereof. 
GA-A22516

CONF-961102--7

\title{
EFFECTS OF EXB VELOCITY SHEAR AND MAGNETIC SHEAR ON TURBULENCE AND TRANSPORT IN MAGNETIC CONFINEMENT DEVICES
}

\author{
by \\ K.H. BURRELL
}

This is a preprint of an invited paper to be presented at the Thirty-Eighth Annual Meeting of the Division of Plasma Physics, November 11-15, 1996, in Denver, Colorado, and to be published in Phys. Plasmas

Work supported by

the U.S. Department of Energy

under Contract Nos. DE-AC03-89ER51114, W-7405-ENG-48, DEAC05-960R22464, DE-AC04-94AL85000, and Grant Nos. DE-FG0291ER54109, DE-FG03-86ER53266, and DE-FG03-95ER54294

GA PROJECT 3466 NOVEMBER 1996 


\section{ABSTRACT}

One of the scientific success stories of fusion research over the past decade is the development of the $\mathrm{E} \times \mathrm{B}$ shear stabilization model to explain the formation of transport barriers in magnetic confinement devices. This model was originally developed to explain the transport barrier formed at the plasma edge in tokamaks after the $\mathrm{L}$ (low) to $\mathrm{H}$ (high) transition. This concept has the universality needed to explain the edge transport barriers seen in limiter and divertor tokamaks, stellarators and mirror machines. More recently, this model has been applied to explain the further confinement improvement from $\mathrm{H}$ (high)-mode to VH (very high)-mode seen in some tokamaks, where the edge transport barrier becomes wider. Most recently, this paradigm has been applied to the core transport barriers formed in plasmas with negative or low magnetic shear in the plasma core. These examples of confinement improvement are of considerable physical interest; it is not often that a system self-organizes to a higher energy state with reduced turbulence and transport when an additional source of free energy is applied to it. The transport decrease that is associated with $\mathrm{E} \times \mathrm{B}$ velocity shear effects also has significant practical consequences for fusion research. The fundamental physics involved in transport reduction is the effect of $\mathrm{E} \times \mathrm{B}$ shear on the growth, radial extent and phase correlation of turbulent eddies in the plasma. The same fundamental transport reduction process can be operational in various portions of the plasma because there are a number ways to change the radial electric field $E_{\mathrm{r}}$. An important theme in this area is the synergistic effect of $E \times B$ velocity shear and magnetic shear. Although the $E \times B$ velocity shear appears to have an effect on broader classes of microturbulence, magnetic shear can mitigate some potentially harmful effects of ExB velocity shear 
and facilitate turbulence stabilization. Considerable experimental work has been done to test this picture of $\mathrm{E} \times \mathrm{B}$ velocity shear effects on turbulence; the experimental results are generally consistent with the basic theoretical models.

PACS Nos. $\underline{52.55}, \underline{52.35 . R}, \underline{52.35 . Q}, \underline{52.30}$ 


\section{INTRODUCTION}

One of the scientific success stories of fusion research over the past decade is the development of the ExB velocity shear model to explain the formation of transport barriers in magnetic confinement devices. This model was originally developed to explain the transport barrier formed at the plasma edge in tokamaks after the $\mathrm{L}$ (low) to $\mathrm{H}$ (high) transition. As has been discussed previously, ${ }^{1}$ this concept has the universality needed to explain the edge transport barriers seen in limiter and divertor tokamaks, stellarators and mirror machines. More recently, this model has been applied to explain the further confinement improvement from $\mathrm{H}$ (high)-mode to VH (very high)-mode seen in some tokamaks, ${ }^{2-4}$ where the edge transport barrier becomes wider. Most recently, this paradigm has been applied to the core transport barriers formed in plasmas with negative or low magnetic shear in the plasma core. $1,5-8$

These examples of confinement improvement are of considerable physical interest; it is not often that a system self-organizes to a higher energy state with reduced turbulence and transport when an additional source of free energy is applied to it. In addition to its intrinsic physics interest, the transport decrease that is associated with EXB velocity shear effects has significant practical consequences for fusion research. For example, the best fusion performance to date in the DIII-D $\mathrm{D}^{9}$ and JT-60U 10 tokamaks has been obtained under conditions where transport reduction through $\mathrm{E} \times \mathrm{B}$ velocity shear decorrelation of turbulence is almost certainly taking place. 11,12 The performance of these discharges represents a revolutionary step forward in the control of plasma turbulence and transport. In the DIII-D case, for example, the ion thermal transport is at the minimum level set by interparticle collisions over the whole discharge. 11 In other words, at least in the ion 
channel, it appears that anomalous transport is much smaller than collision-induced transport.

The fundamental physics involved in transport reduction is the effect of $\mathrm{E} \times \mathrm{B}$ velocity shear on the growth of and radial extent of turbulent eddies in the plasma. Both nonlinear decorrelation ${ }^{13-17}$ and linear stabilization ${ }^{18-23}$ effects have been considered. The basic nonlinear effect is the reduction in radial transport owing to decrease in the radial correlation length and the change in the phase between density, temperature and potential fluctuations. There are a multitude of linear effects specific to various modes; however, one general feature of linear stabilization is coupling to more stable modes caused by the E $\times B$ velocity shear.

The same fundamental transport reduction process can be operational in various portions of the plasma because there are a number ways to change the radial electric field $E_{\mathrm{r}}$. The radial force balance equation

$$
E_{\mathrm{r}}=\left(Z_{\mathrm{i}} e n_{\mathrm{i}}\right)^{-1} \nabla P_{\mathrm{i}}-v_{\theta \mathrm{i}} B_{\phi}+v_{\phi \mathrm{i}} B_{\theta}
$$

indicates that there is a connection between $E_{\mathrm{r}}$ and the cross field heat and particle transport $\left(\nabla P_{\mathbf{i}}\right)$, cross field angular momentum transport $\left(V_{\varphi \mathrm{i}}\right)$ and poloidal flow $\left(V_{\theta_{\mathbf{i}}}\right)$. Since sheared $E \times B$ flow also affects turbulence and transport, there are several feedback loops whereby $E_{\mathrm{r}}$ and its shear can change, allowing the plasma access to different confinement regimes. For example, both $v_{\theta i}$ and $\nabla P_{i}$ are important in the H-mode edge 1 while $v_{\varphi \mathrm{i}}$ appears to play the major role in $\mathrm{VH}-$ mode. ${ }^{2-4}$ Both $v_{\varphi i^{6}}{ }^{6}$ and $\nabla P_{i}{ }^{7}$ appear to play a role in the core transport barriers. This multiplicity of feedback loops ultimately provides a number of possibilities for active control of transport. Neutral beam injection, for example, has been used to alter $v_{\varphi i^{2}}{ }^{2-7}$ while ion Bernstein wave input may have produced effects consistent with a change in $v_{\theta i} \cdot 24$ 
One of the important themes in this area is the synergistic effects of $E \times B$ velocity shear and magnetic shear. Although the ExB velocity shear appears to have an effect on broader classes of microturbulence, magnetic shear can mitigate some potentially harmful effects of $E \times B$ velocity shear and facilitate turbulence stabilization. For example, there are many similarities in velocity shear effects in magnetized plasmas and neutral fluids; 25 however, in neutral fluids, the increased turbulent drive owing to the free energy provided by the velocity shear usually overcomes the stabilizing effects of reduced radial correlation length to drive Kelvin-Helmholtz instabilities. In a plasma with magnetic shear, both in the ideal case 26 and the resistive case, ${ }^{14}$ Kelvin-Helmholtz modes are rendered ineffectual. As a second example, in the case of core transport barriers, the magnetic shear effects play a role by linearly stabilizing several modes (e.g. sawteeth and ideal ballooning modes) while reducing the growth rates of others, 11,27,28 thus allowing the core gradients to steepen. A transport bifurcation, similar to those previously discussed, 29,30 results and the core transport barrier forms. $27-30$

Considerable experimental work has been done to test this picture of ExB velocity shear effects on turbulence. As will be discussed in detail in this paper, the experimental results are consistent with the basic theoretical models. The EXB velocity shear model has the universality needed to explain: 1) $\mathrm{H}$-mode edge confinement improvement seen in limiter and divertor tokamaks, stellarators, torsatrons and mirror machines produced with a variety of heating and plasma biasing schemes; 2) the confinement improvement in the outer half of the plasma seen in VH-mode and high internal inductance discharges 31 and 3) the formation of core transport barriers in a number of tokamaks. In addition, there is both qualitative and quantitative agreement between theory and the experimental results. Finally, in the last several years, there have been several rigorous tests of causality; the experimental results are consistent with $\mathrm{E} \times \mathrm{B}$ velocity shear causing the reduction in turbulence and transport in both the plasma edge and the core. 
The goal of this paper is to give a summary of the theoretical picture of ExB velocity shear decorrelation and suppression of turbulence and then to review experimental results which provide tests of this model. The theory is reviewed in Section II while the experimental results are considered in the remaining sections. 


\section{THEORY}

\section{A. Basic theoretical model}

There are two themes which wind through the theory of $\mathrm{E} \times \mathrm{B}$ velocity shear effects on turbulence. The first is (nonlinear) decorrelation of turbulence, leading to a reduction in transport ${ }^{13-17}$ even though the underlying turbulence is not completely suppressed. The second is (linear) stabilization of modes leading to transport reduction through complete stabilization. Examples of the latter effect are given in Refs. [18-23].

An illustration of turbulence decorrelation is given in Figs. 1 and 2. In this simple model, ${ }^{32}$ density is treated as a passive scalar, affected by the velocity field of turbulent eddies. As is illustrated in Fig. 1, with no velocity shear, the eddies coupled with a linear background density profile produce hills and valleys in the density spatial distribution. As is shown in Fig. 2, the correlation between the density and velocity perturbations then leads to radial transport. When a shear in the average velocity is added to the problem, the eddies are distorted and, as is shown in Fig. 2, radial transport is reduced. This reduction is due both to changes in the phase relationship between the density and velocity perturbations and to decreases in the amplitude of the turbulent fluctuations.

The simple model shown in Figs. 1 and 2 is highly idealized. However, it retains the important features first discussed in the analytic models ${ }^{14}$ and that are also seen in much more elaborate numerical calculations. ${ }^{22,33-35}$ The ability of ExB velocity shear to affect even nonlinearly saturated turbulence is important in the overall picture, since it 


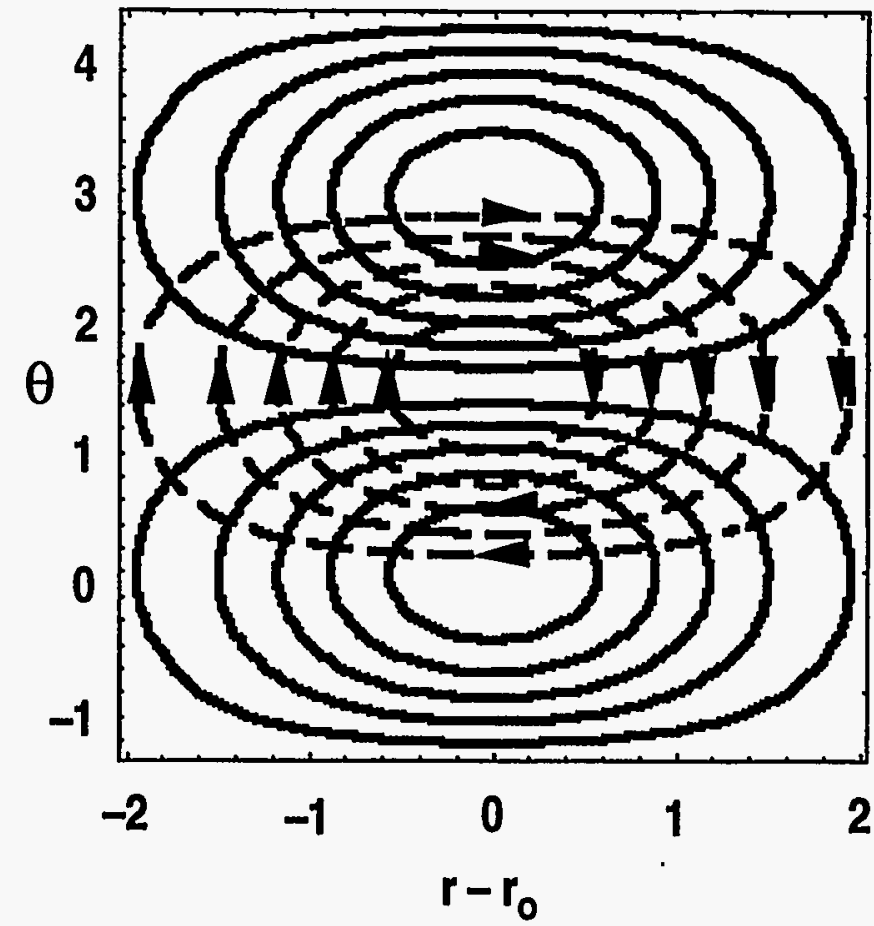

$\tilde{n}>0$

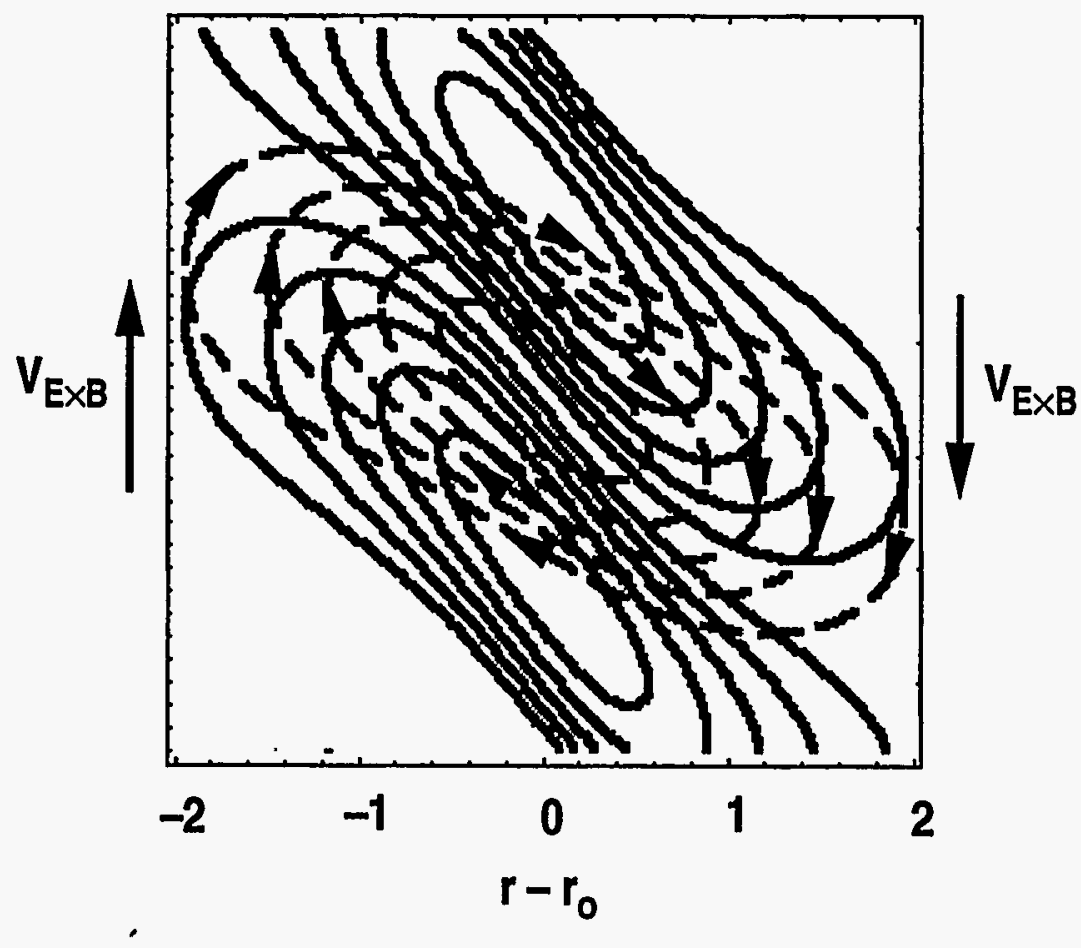

$\tilde{n}<0$

Fig. 1. Results of a simple model of turbulence which treats density as a passive scalar, convected by the eddy velocity field. The calculation is done in a cylindrical $(r, \theta)$ geometry. In (a) there is no shear in the average velocity while in (b) an average velocity with a linear gradient is imposed on the system. The sheared average flow distorts the turbulent eddies and leads to decorrelation between the density and velocity perturbations. This decorrelation is manifested in the sheared case in the difference in the angle that the major axes of the density and velocity ellipses make with each other and by the twisting in the density ellipses as one moves away from the density maximum or minimum. 


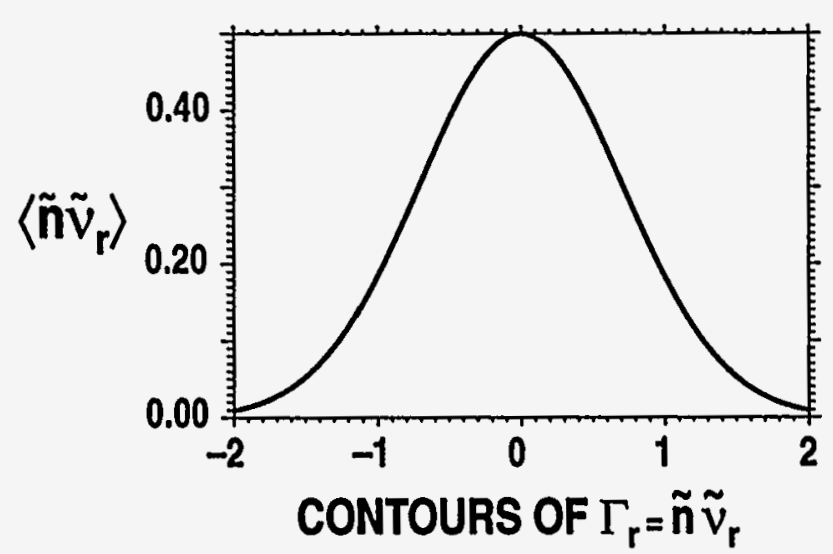

(a)

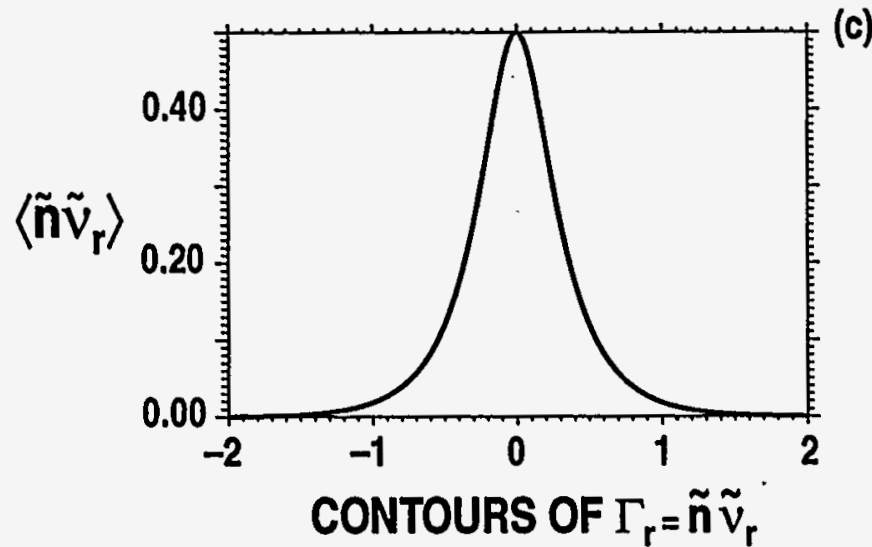



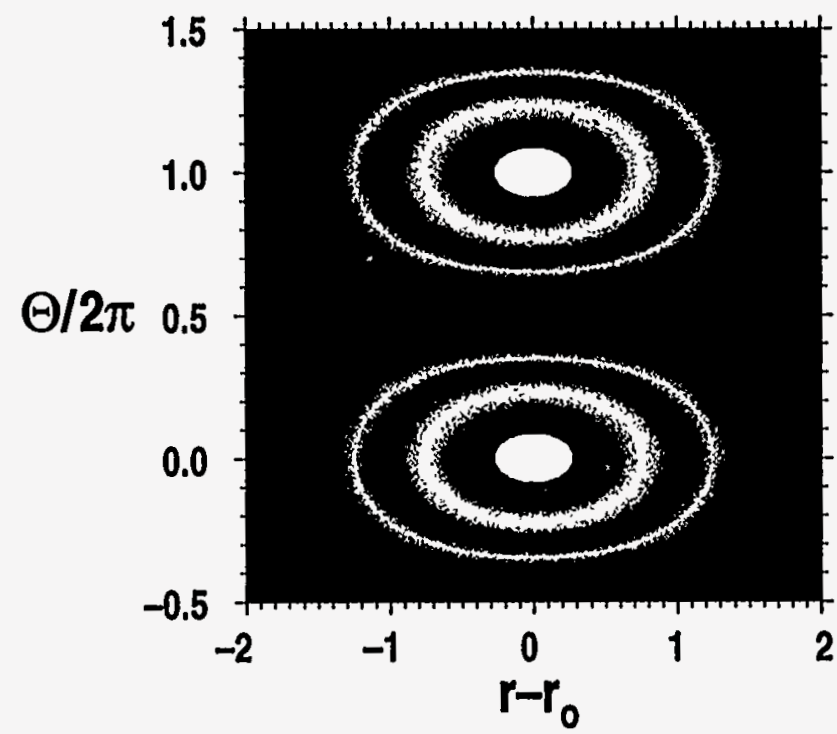

(b)

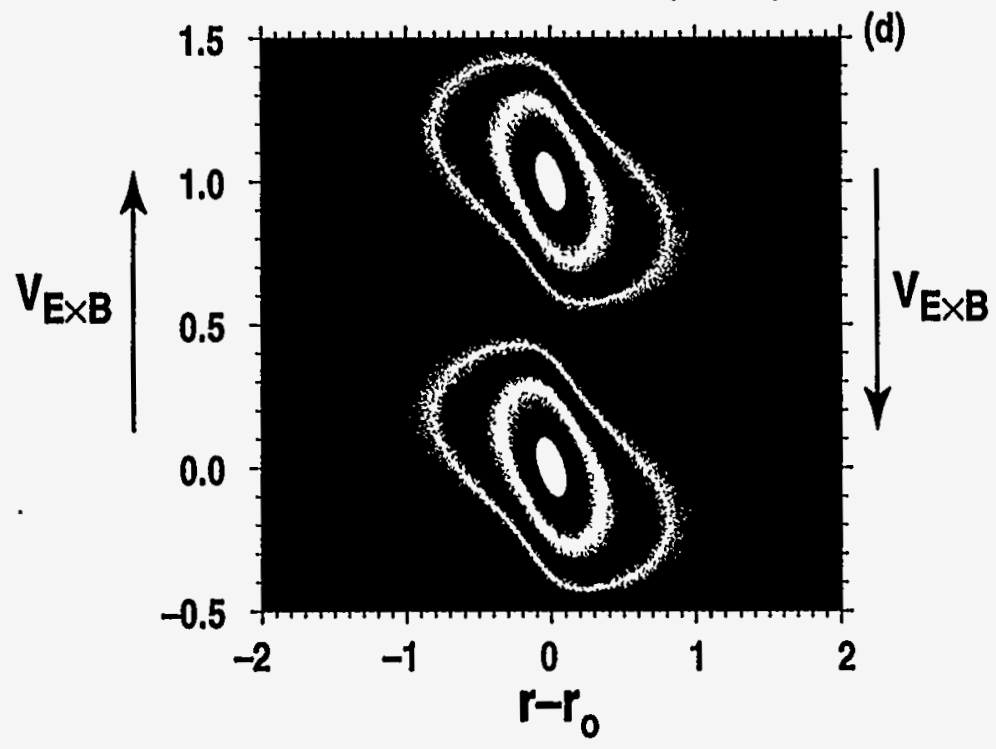

Fig. 2. The radial particle flux in $v_{\mathrm{r}}$ for the model shown in Fig. 1. The (a) and (b) plots are for no shear in the average velocity while (c) and (b) are for the sheared case. The (b) and (d) plots are color coded contours of the radial flux in the $(\rho, \theta)$ plane while the (a) and (c) plots are the radial flux averaged over the theta coordinate. The distortion of the eddies in (d) compared to (b) shows the effect of velocity shear on the radial flux. In addition, at points away from the maximum, the radial flux decreases strongly in the sheared case. The net radial flux [the integral under the curves in (a) and (d)] decreases significantly owing to the velocity shear. 
provides a mechanism whereby the plasma can start in a highly turbulent, poor confinement state and move to an improved confinement state with reduced turbulence.

The linear stability effects of $\mathrm{E} \times \mathrm{B}$ velocity shear are more difficult to discuss in general, since much of the physics is mode specific. ${ }^{18-23}$ However, there is one general effect that appears to persist across a number of different modes. The presence of $E \times B$ velocity shear results in enhanced damping by coupling the unstable modes to other, nearby, stable modes, thus improving the overall stability of the system. Often, this coupling leads to increased Landau damping of the modes. ${ }^{20,22}$ Magnetic shear is often helpful in this process; however, complete $\mathrm{E} \times \mathrm{B}$ velocity shear stabilization is possible even in the absence of magnetic shear. 18

\section{B. Frequently asked questions}

There are several key questions about $\mathrm{E} \times \mathrm{B}$ velocity shear effects which cause confusion. The first of these concerns the central role that $\mathrm{E} \times \mathrm{B}$ velocity shear is assigned in the theory. In general, one might think that shear in any component of any species' velocity could be significant. The central role of $E \times B$ velocity shear can be looked at in two ways. The formal mathematical answer has been provided by Kim et al. 36 through a careful, general toroidal geometry derivation of the equations governing electrostatic, flute-like modes. This work clearly shows that, for such modes, the only convective term in the equations is the $\mathrm{E} \times \mathrm{B}$ drift. Accordingly, the $\mathrm{E} \times \mathrm{B}$ velocity acquires a special place in the theory. What measurements there are in tokamaks 37,38 indicate that fluctuations are indeed flute-like, although these measurements were made near the plasma edge.

There is another way to understand why $\mathrm{E} \times \mathrm{B}$ shear is fundamental. For any particular mode in the plasma, the actual phase and group velocities of the turbulence can 
be complicated functions of the plasma parameters. However, all particles move with the EXB velocity, regardless of their charge or mass. Accordingly, the $\mathrm{E} \times \mathrm{B}$ velocity contributes to all modes. Consequently, any mode that can be affected by sheared velocity will be affected by sheared $E \times B$ velocity provided the $E \times B$ velocity shear is sufficiently large. In this sense, $\mathrm{E} \times \mathrm{B}$ velocity shear provides a universal mechanism for affecting turbulence.

A second confusing point has to do with the difference between the poloidal rotation of the various ions in the plasma and the $\mathrm{E} \times \mathrm{B}$ flow velocity. This confusion comes about partially because the initial theories of velocity shear effects on the $\mathrm{H}$-mode were done in cylindrical geometry 14,15 for a plasma with one ion species. For this case, there is little distinction between the fluid velocity perpendicular to $\mathbf{B}$ and the $\mathrm{E} \times \mathrm{B}$ velocity. In addition, this confusion may partially have resulted from the initial $\mathrm{H}$-mode observations of changes in the radial electric field $E_{\mathrm{r}}$ across the $\mathrm{L}$ to $\mathrm{H}$ transition which were based on observations of changes in the poloidal flow of impurity ions. 39,40 However this confusion came about, as is shown in Fig. 3, the ExB drift speed is very different from the poloidal rotation speed of the main ions and the poloidal rotation speed of the most significant impurity ion. 41 The main ion and impurity poloidal rotation speeds do not even have the same sign. Furthermore, the shear in the three different speeds are also clearly different. Accordingly, since the theory speaks in terms of shear in the $E \times B$ velocity, one really cannot substitute the ion poloidal rotation speed for this.

The final frequently asked question has to do with the velocity shear itself driving turbulence. Although there are several instances in neutral fluids of velocity shear reducing transport, $25,42-44$ in neutral fluid dynamics one usually thinks of sheared velocity as a source of free energy which can drive turbulence through Kelvin-Helmholtz 


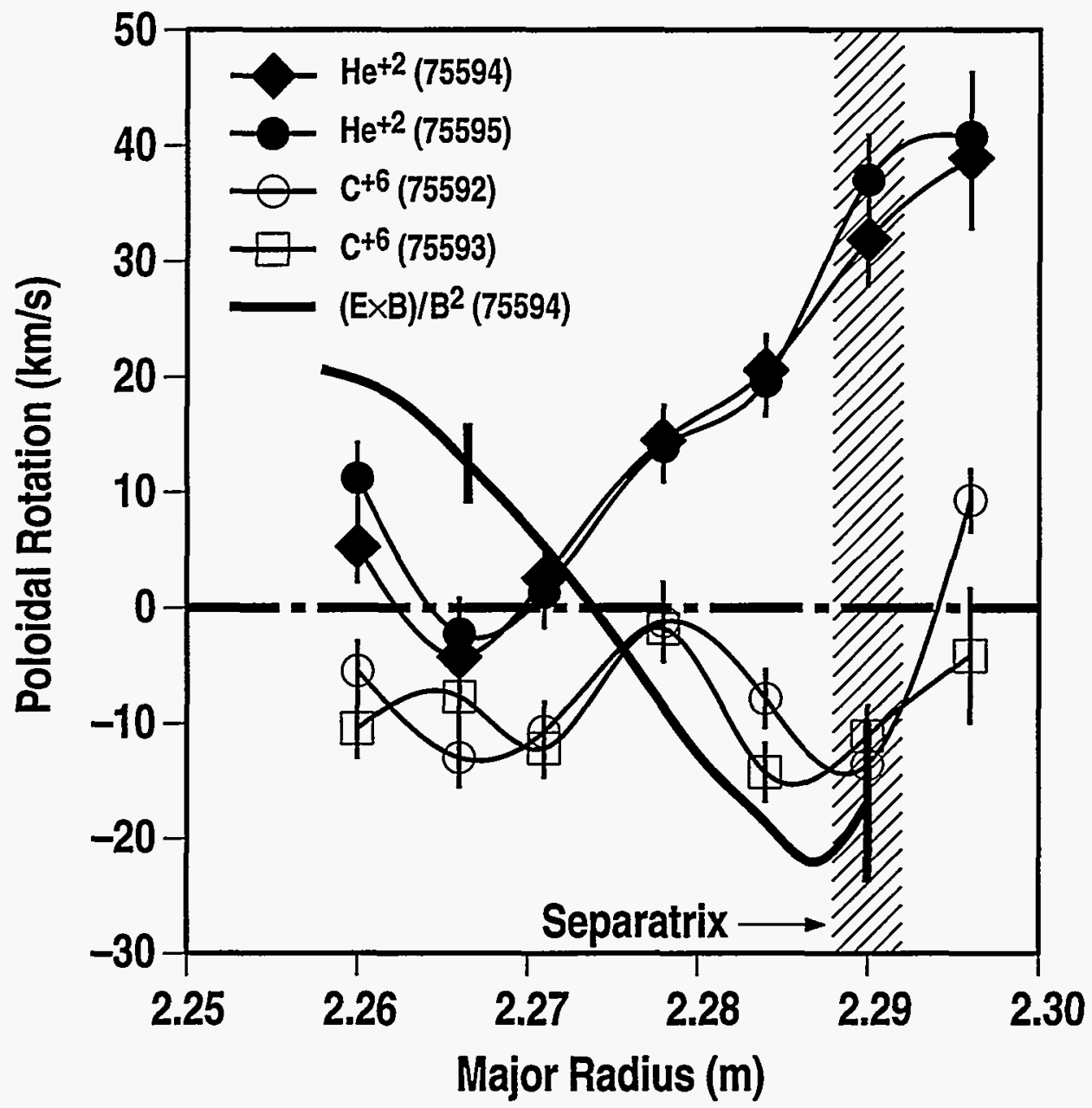

Fig. 3. The poloidal rotation speed of the main plasma ion $\left(\mathrm{He}^{+2}\right)$, the most significant impurity ion $\left(\mathrm{C}^{+6}\right)$ and the $\mathrm{E} \times \mathrm{B}$ drift speed in the edge of an $\mathrm{H}$-mode plasma in DIII-D showing the significant difference in the three speeds. Data from Ref. [41]. Plasma conditions are 1.0 MA plasma current, 2.0 T toroidal field, $6.7 \mathrm{MW}$ injected deuterium neutral beam power and $2.2 \times 10^{19} \mathrm{~m}^{-3}$ line averaged density. Discharge is a single-null divertor with the $\nabla \mathrm{B}$ drift towards the X-point.

instabilities. ${ }^{45}$ Fortunately, in a plasma, magnetic shear is capable of rendering KelvinHelmholtz modes ineffectual. One can think of this problem in analogy to other plasma instabilities (e.g. ballooning modes or drift waves) as having possibilities for both ideal and resistive instabilities. For the ideal case, ${ }^{26}$ the stability criterion can be stated as $\left(\nabla E_{\mathrm{r}} / B\right)<\left(V_{\mathrm{A}} / L_{\mathrm{S}}\right)$, where $B$ is the magnitude of the magnetic field, $V_{\mathrm{A}}$ is the Alfvèn speed and $L_{\mathrm{S}}$ is the magnetic shear length. The physical basis for the stabilization is that shear in the magnetic field prevents coupling of the various modes across the velocity 
gradient so that they are unable to extract energy from the ExB velocity shear and grow. The steepest gradients in $E_{\mathrm{r}}$ are observed at the edge of $\mathrm{H}$-mode plasma; however, even there the $\nabla E_{\mathrm{r}} / B$ is insufficient for ideal instability for typical parameters. If finite resistivity $\eta$ is assumed, then the modes can slip past the magnetic field and still extract energy from the velocity shear. However, the presence of ExB velocity shear also acts as a decorrelation mechanism. Accordingly, the criterion for preventing significant KelvinHelmholtz instability is 14

$$
\frac{\nabla E_{r}}{E_{r}}<\left(\frac{1}{\eta \Delta \omega_{\mathrm{D}}}\right)^{1 / 4}\left(V_{\mathrm{A}} k_{\mathrm{y}} / L_{\mathrm{s}} c\right)^{1 / 2}
$$

where $\Delta \omega_{\mathrm{D}}$ is the turbulence decorrelation rate and $k_{\mathrm{y}}$ is the poloidal wavenumber of the turbulent mode. Again, this criterion would be most easily violated at the plasma edge in $\mathrm{H}$-mode, where $\nabla E_{\mathrm{r}}$ and $\eta$ are the largest. Using typical $\mathrm{H}$-mode tokamak edge parameters shows that there is no significant instability.

\section{General geometry and decorrelation and stabilization criteria}

Early theory on $E \times B$ shear stabilization of turbulence was done in cylindrical geometry. 14-15 Recently, in order to deal with the true geometry of tokamaks, the twopoint analysis has been extended to general tokamak flux surface geometry, 46 yielding an expression for the $\mathrm{E} \times \mathrm{B}$ shearing rate for flute-like modes

$$
\omega_{\mathrm{E} \times \mathrm{B}}=\frac{\Delta \psi_{\mathrm{o}}}{\Delta \phi}\left(\frac{\partial}{\partial \psi}\right) \frac{E_{r}}{R B_{\theta}},
$$

where $L_{\mathrm{r}}=\Delta \psi_{0} / R B_{\theta}$ is the radial correlation length, $R \Delta \varphi$ is the toroidal correlation length of the ambient turbulence, $R$ is the major radius and $B_{\theta}$ is the poloidal magnetic field. For flute-like modes, the poloidal correlation length is $L_{\theta}=R B_{\theta} \Delta \phi / B_{\phi}$ while the 
correlation length perpendicular to the field line but in the flux surface is $L_{\perp}=R B_{\theta} \Delta \phi / B$; here, $B_{\phi}$ is the toroidal magnetic field and $B$ is the magnitude of the magnetic field. In many cases, measurements of $L_{\mathrm{r}}$ and $L_{\perp}$ are not available. Motivated by numerical simulations which show $L_{\perp} \cong L_{\mathrm{r}}, 33,47,48$ the assumption $L_{\perp}=L_{\mathrm{r}}$ can be used to reduce Eq. (2) to

$$
\omega_{\mathrm{E} \times \mathrm{B}}=\frac{\left(R B_{\theta}\right)^{2}}{B}\left(\frac{\partial}{\partial \psi}\right) \frac{E_{\mathrm{r}}}{R B_{\theta}} .
$$

There is also experimental evidence that $L_{\perp}$ and $L_{\mathrm{r}}$ are nearly equal. 49 The EXB shearing rate actually enters into the various theories quadratically; 14,46 accordingly, the sign of $\omega_{\mathrm{E} \times \mathrm{B}}$ is irrelevant. Indeed, $\mathrm{H}$-mode edge barriers have been seen with both signs of $E_{\mathrm{r}}$ and its derivative. 1

The functional forms in Eqs. (2) and (3) have several interesting features. The

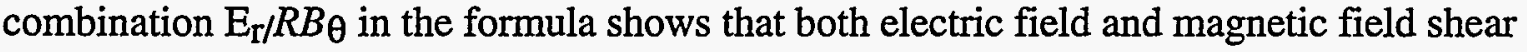
are contributing to the final result. Second, under the usual neoclassical assumptions, $E_{\mathrm{r} /} R B_{\theta}$ is constant on a flux surface because the lowest order electrostatic potential is a flux function. However, since $\left(R B_{\theta}\right)^{2} / B$ varies on a flux surface, so does $\omega_{E \times B}$. Third, $E_{\mathrm{r} /} / R B_{\theta}$ is the toroidal angular speed due to the equilibrium flow driven by $E_{r}$ in standard neoclassical theory. This suggests, and the basic equations confirm, 46 that the basic shearing is in the toroidal direction for flute-like modes in toroidal geometry. Finally, the form in Eq. (3) agrees with the results of previous, large aspect ratio derivations $18,50,51$ in that limit, although some diamagnetic drift terms must be neglected to produce exact agreement with Refs. [18, 50].

As is illustrated in Fig. 4, the differences between the shear in $E_{\mathrm{r}} / B$ and in $E_{\mathrm{r} /} R B_{\theta}$ has great practical significance. As is shown there, $E_{\mathrm{r}}$ has a local maximum around $\rho=0.5$ in 


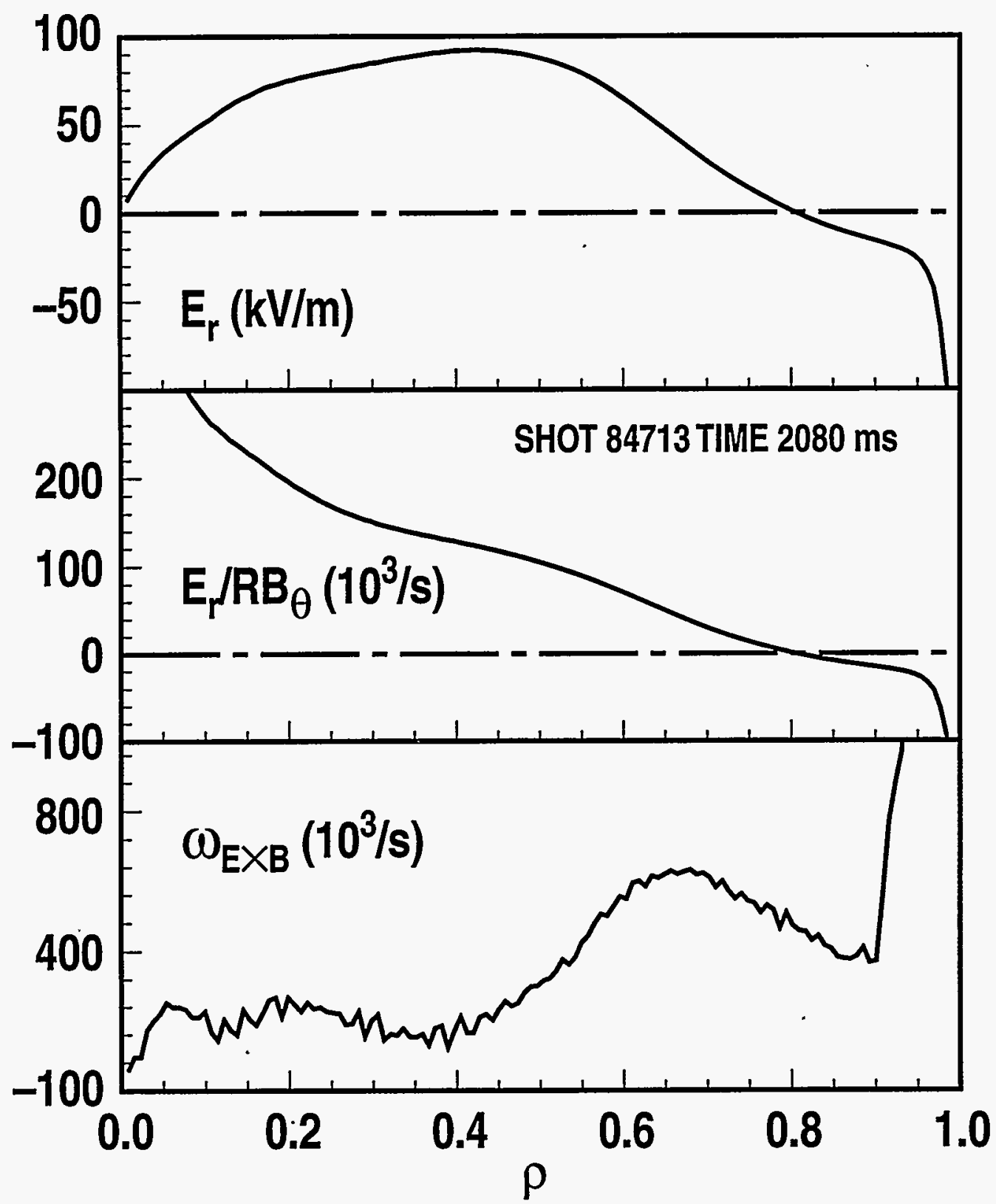

Fig. 4. Plot of radial electric field $E_{\mathrm{r}}$, toroidal angular speed $E_{\mathrm{r}} / R B_{\theta}$ and the ExB shearing rate defined in $E q$. . (3) as a function of flux surface label $r$ for a high performance, deuterium VH-mode plasma in DIII-D. Here, $\rho$ is proportional to the square root of the toroidal flux inside a given flux surface. Although the derivative of $E_{\mathrm{r}}$ vanishes near $\rho=0.5$, the EXB shearing rate is appreciable across the whole plasma. Plasma conditions are 1.2 MA plasma current, 1.6 T toroidal field, 9.8 MW injected deuterium neutral beam power and $4.7 \times 10^{19} \mathrm{~m}^{-3}$ line averaged density. Discharge is a double-null divertor. 
this particular plasma, indicating that the shear in $E_{\mathrm{r}} / B$ would vanish near that point. $E_{\mathrm{r} /} / R B_{\theta}$, on the other hand, has its maximum on the magnetic axis and has a significant derivative throughout the plasma, as is illustrated by the plot of $\omega_{\mathrm{E} \times \mathrm{B}}$. Indeed, this particular plasma shows confinement improvement across the whole minor radius. ${ }^{6}$

For $\mathrm{E} \times \mathrm{B}$ shear decorrelation of turbulence, $\omega_{\mathrm{E} \times \mathrm{B}}$ must be comparable to $\Delta \omega_{\mathrm{D}}$, the nonlinear turbulence decorrelation rate in the absence of $E \times B$ shear. ${ }^{14,46}$ Although $\Delta \omega_{D}$ can be calculated for some cases, 22,35 it is not routinely available for comparison with experiment. Recent nonlinear gyro Landau fluid simulations have also shown complete turbulence stabilization when $\omega_{\mathrm{E} \times \mathrm{B}}$ is comparable to $\gamma_{\mathrm{MAX}}$, the maximum linear growth rate of all the unstable modes in the plasma. ${ }^{18,33}$ This rule $\omega_{\mathrm{E} \times \mathrm{B}}=\gamma_{\mathrm{MAX}}$ has thus been used in several comparisons between theory and experiment 6,7 and will be used later in this paper. It should be noted, however, that even the original numerical calculations on which this rule is based 18 showed up to factors of 2.5 deviation from this rule for turbulence stabilization. In other words, in some cases it took an $\omega_{\mathrm{E} \times \mathrm{B}}$ a factor of two smaller that $\gamma_{\mathrm{MAX}}$ for complete stabilization while in other cases $\omega_{\mathrm{E} \times \mathrm{B}}$ had to exceed $\gamma_{\text {MAX }}$ by a factor of 2.5. Accordingly, this rule can only be taken as a rough rule of thumb. Equation (3) shows that $\omega_{\mathrm{E} \times \mathrm{B}}$ is not constant on a magnetic surface. Accordingly, there is a question of where to make the comparisons between $\omega_{\mathrm{E} \times \mathrm{B}}$ and $\gamma_{\text {MAX. The stability codes used to evaluate }} \gamma_{\text {MAX }}$. T2-55 typically find the fastest growing modes along the low toroidal field side of a given flux surface. The $\omega_{\mathrm{E} \times \mathrm{B}}$ quoted in comparisons in this paper, unless otherwise noted, is evaluated at that point on the flux surfaces.

Finally, in comparing $\omega_{\mathrm{E} \times \mathrm{B}}$ to $\Delta \omega_{\mathrm{D}}$ or $\gamma_{\mathrm{MAX}}$, we end up confronting the relative roles of a large number of plasma parameters. For example, for trapped electron modes and/or ion temperature gradient driven modes, $\gamma_{\text {MAX }}$ depends at least on magnetic shear, 
ion to electron temperature ratio $T_{\mathrm{i}} / T_{\mathrm{e}}$, impurity concentration in the plasma and the Shafranov shift of the magnetic axis. Accordingly, in a given situation, all of these can influence how much ExB velocity shear is needed to affect the turbulence. In that sense, any quantity which significantly affects the $\Delta \omega_{D}$ or $\gamma_{\text {MAX }}$ can be important in the physics. On the other hand, there is evidence, presented in Section IV, that it is the ExB velocity shear that is the important feature in producing the reduced transport, since there are many cases where $\gamma_{\text {MAX }}$ is observed to increase in the region where transport and fluctuations are reduced.

\section{Curvature effects}

Much of the theoretical work on ExB shear stabilization effects only considers the effect of the first derivative of the ExB velocity. However, as has been considered by several authors $20,23,56-58$ stabilization effects due to a non-zero second derivative (curvature) of the $\mathrm{E} \times \mathrm{B}$ veloctiy are also possible. Unlike the first derivative case, the stabilization effects of curvature depend on the sign of the curvature. Furthermore, whether a given sign is stabilizing or destabilizing is mode specific. For example, calculations for ion temperature gradient (ITG) 20,23 and dissipative trapped electron modes (DTE) indicate that positive $E_{\mathrm{r}}$ curvature (an $E_{\mathrm{r}}$ well) is stabilizing for ITG modes and destabilizing for DTE modes. Positive $E_{\mathrm{r}}$ curvature is destabilizing for electron drift waves provided that the $E_{\mathrm{r}}$ well is deep enough. 56,57

The nonlinear effects of $E_{\mathrm{r}}$ curvature result in a radial squeezing or broadening of the turbulent eddies, depending on the sign of the curvature. Squeezing produces reduced radial correlation lengths and reduced transport, similar to a linear variation in the $E \times B$ flow. 


\section{H-MODE EDGE RESULTS}

$\mathrm{H}$-mode edge transport barrier studies provide the largest body of data for testing the EXB velocity shear theory. The results show qualitative and quantitative agreement with the theory. In addition, in the last few years, several results have been produced which are consistent with $\mathrm{E} \times \mathrm{B}$ shear causing changes in turbulence and transport.

The $\mathrm{H}$-mode was first discovered in ASDEX, a divertor tokamak, 59 but has now been seen in a wide variety of magnetic confinement devices. $\mathrm{H}$-mode has been obtained in all auxiliary-heated divertor tokamaks that have operated since 1982, in limiter discharges in several tokamaks, ${ }^{60-63}$ in a current-free stellarator, 64,65 in a heliotron/ torsatron 66,67 and in a linear tandem mirror machine. $68,69 \mathrm{H}$-mode has also been produced with a wide variety of techniques: heating with neutral beam injection on many machines, electron cyclotron heating, $64,65,70,71$ ion cyclotron heating, ${ }^{60,72}$. lower hybrid heating ${ }^{73}$ and Ohmic heating. ${ }^{74-77}$ Furthermore, H-mode has also been produced by biasing the plasma using an external electrode $75,78,79$ or by biasing the limiter. 68,69 Since the advent of biased $\mathrm{H}$-modes, ${ }^{75,78,79} \mathrm{H}$-modes produced by heating the plasma have been referred to as spontaneous $\mathrm{H}$-mode.

Because the $\mathrm{H}$-mode confinement improvement appears in many magnetic configurations and has been produced by many means, it is clear that the explanation of the results requires some mechanism with significant universality. A theory that is specific to a given magnetic configuration or to a specific heating mechanism would not be consistent with the experimental results. The reduction in turbulence-driven transport by $\mathrm{E} \times \mathrm{B}$ velocity shear has this universality. 
There is a set of common features that are seen in all devices which obtain $\mathrm{H}$-mode. The first to be identified was the formation of a transport barrier at the plasma edge 80 where the density and temperature gradients steepen after the transition. The formation of this barrier is associated with a drop in the $D_{\alpha}$ radiation all around the plasma, indicating a significant decrease in the particle outflux. In addition, later work showed that the density fluctuation amplitude decreases in the region where the transport barrier forms. ${ }^{81-83}$ Finally, at the same time as the formation of the transport barrier and the reduction in fluctuations, a steep gradient region develops in $E_{\mathrm{r}}$ at the plasma edge. 39,40 These features have been seen in all tokamak discharges where diagnostics capabilities allow it 84,85 and have also been seen in the stellarator $86-88$ and mirror results. 68,69 This spatial and temporal correlation between increased $\mathrm{E} \times \mathrm{B}$ shear, turbulence reduction and transport reduction demonstrates qualitative consistency between the theory of $E \times B$ velocity shear stabilization of turbulence and the experimental results.

Theory predicts that radial, fluctuation-driven transport should be reduced if the $E \times B$ shearing rate is large enough. Langmuir probe measurements in the plasma edge in spontaneous $\mathrm{H}$-modes 89,90 and biased $\mathrm{H}$-mode 91,92 in tokamaks and in the Wendelstein 7-AS stellarator 88 show large decreases in the fluctuation-driven particle flux, consistent with the theoretical expectation.

The functional form in Eq. (3) predicts that $\omega_{\mathrm{E} \times \mathrm{B}}$ is not constant on a flux surface, being significantly larger on the low toroidal field side of the flux surface. Accordingly, one might expect significant poloidal variation in the effect of $E \times B$ shear on turbulent fluctuations. Experimental measurements at the inner and outer midplane of the edge plasma in $\mathrm{H}$-mode have indeed shown such differences, ${ }^{84,93}$ which are qualitatively consistent with the factor of six variation in $\omega_{\mathrm{E} \times \mathrm{B}}$ between the two sides of the flux surface seen in the experiments. 
In addition to qualitative agreement, there is quantitative agreement between the $\mathrm{E} \times \mathrm{B}$ velocity shear stabilization theory and $\mathrm{L}$ to $\mathrm{H}$ transition experiments. The $\omega_{\mathrm{E} \times \mathrm{B}}$ values from Eq. (2) have been compared with the measured turbulence decorrelation rates in several devices. $84,89,93-95$ The results show that $\omega_{\mathrm{E} \times \mathrm{B}}$ increases significantly as the plasma goes from $\mathrm{L}$-mode to $\mathrm{H}$-mode and $\omega_{\mathrm{E} \times \mathrm{B}}$ significantly exceeds $\Delta \omega_{\mathrm{D}}$ in the $\mathrm{H}$-mode. $\omega_{\text {ExB }}$ significantly exceeding $\Delta \omega_{\mathrm{D}}$ has also been seen in the Ohmic shear layer in the edge of the TEXT tokamak ${ }^{37}$ where turbulence and transport are reduced. An example of such a comparison is given in Fig. 5. For this comparison, the radial correlation length and intrinsic turbulence decorrelation time is obtained from phase contrast imaging 96 while the estimate of the poloidal correlation length is derived from far infra-red scattering. 97 As can be seen in Fig. 5, the ExB shearing rate is comparable to the intrinsic turbulence decorrelation rate in the L-mode but is much larger than it in $\mathrm{H}$-mode. This is what the theory would predict. 14,46

A key prediction of the $\mathrm{E} \times \mathrm{B}$ velocity shear theory is the prediction that $\mathrm{E} \times \mathrm{B}$ velocity shear causes the reduction in turbulence and transport. Causality can be quite difficult to pin down in spontaneous $\mathrm{H}$-modes, since the $E_{\mathrm{r}}$ shear also participates in a number of feedback loops in which changes in transport lead to changes in $E_{\mathrm{r}}$. One way to test causality for the spontaneous $\mathrm{H}$-mode transition is to look for cases where the $E_{\mathrm{r}}$ evolves significantly prior to the $\mathrm{L}$ to $\mathrm{H}$ transition. Over the past two years, the DIII-D group has published several papers showing that the $\mathrm{E} \times \mathrm{B}$ shear changes prior to changes in the turbulence and transport. $90,98-100$ This observation is consistent with causality.

- Another way to approach the causality question is to look at $\mathrm{H}$-modes produced by biasing the plasma. $75,78,79,91,92$ In these cases, the experimenter controls $E_{\mathrm{r}}$ and causality is easier to determine, since the $E_{\mathrm{r}}$ can be varied at will. The existence of biased $\mathrm{H}$-mode itself is a strong argument for $\mathrm{E} \times \mathrm{B}$ shear causing turbulence reduction and 

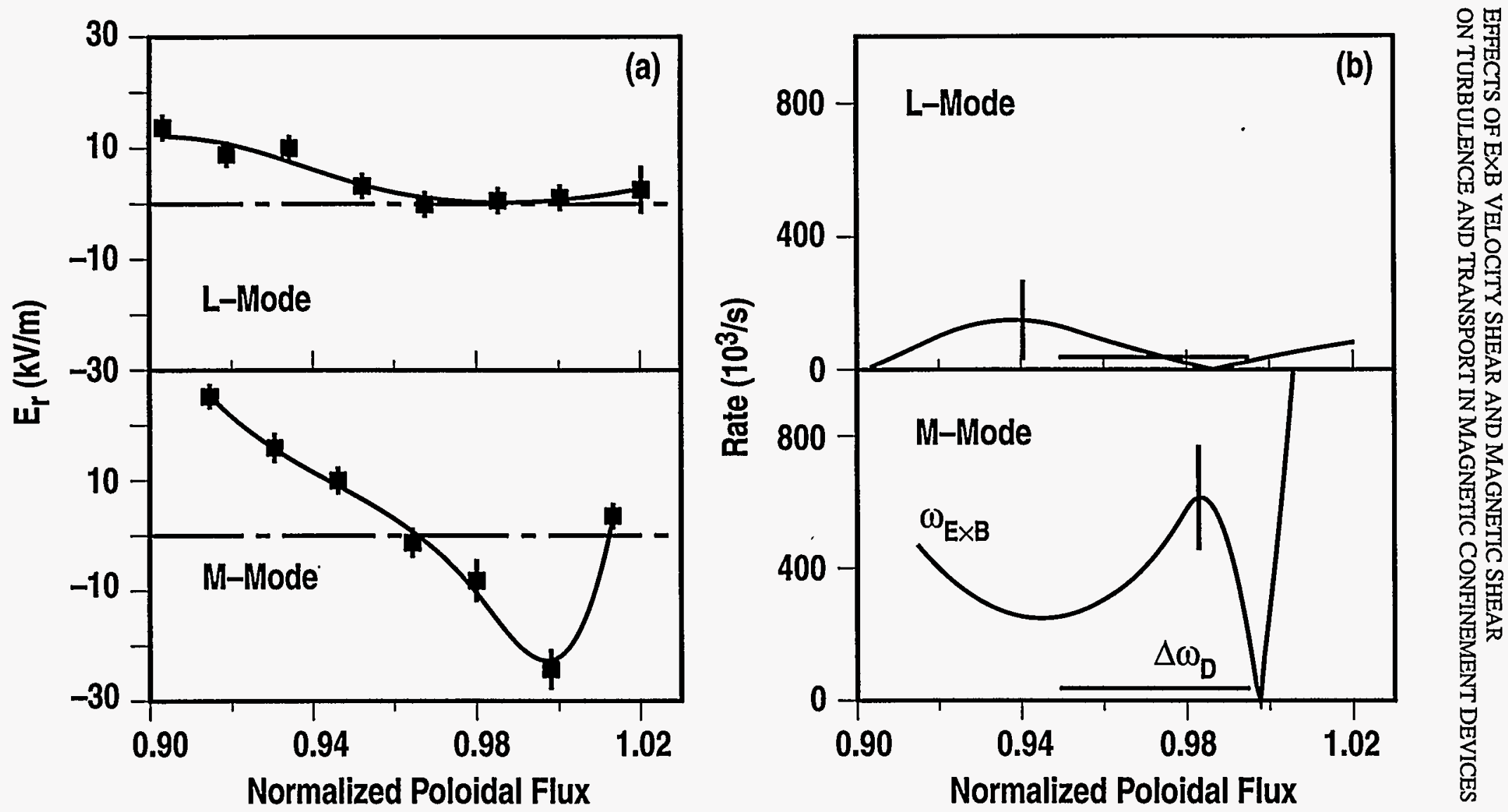

Fig. 5. Comparison of L-mode and $\mathrm{H}$-mode edge profiles in DIII-D near the time of the $\mathrm{L}$ to $\mathrm{H}$ transition.. The $\mathrm{L}$-mode time is about $25 \mathrm{~ms}$ prior to the start of the dithering transition while the $\mathrm{H}$-mode time is $50 \mathrm{~ms}$ later in the quiescent $\mathrm{H}$-mode phase. In $(\mathrm{a})$, the $E_{\mathrm{r}}$ profiles are shown; notice the characteristic $E_{r}$ well at the plasma edge in $\mathrm{H}$-mode. In (b) the ExB shearing rate from Eq. (2) is compared to the intrinsic furbulence decorrelation rate. Turbulence decoerrelation rate and the radial correlation length $(1.15 \mathrm{~cm} \pm 0.15 \mathrm{~cm})$ are determined from phase contrast imaging while the estimate for the poloidal correlation length $(3 \pm 1 \mathrm{~cm})$ is derived from far infra-red scattering. Because the need to use several phase contrast chords to obtian the radial correlation length, the value is plotted as the average value over the region sampled. Plasma conditions $1.5 \mathrm{MA}$ plasma current, $2.2 \mathrm{~T}$ toroidal field, $8.6 \mathrm{MW}$ injected deuterium neutral beam power and $3.6 \times 10^{19} \mathrm{~m}$ line-averaged density. Plasma is a double null divertor operated in deuterium. 
transport improvement, since it is the EXB shear that the experimenter is changing. A recent experiment on TEXTOR (Tokamak Experiment for Technology Oriented Research) ${ }^{101}$ has produced some very clear evidence that $E \times B$ shear influences transport. In this experiment, the electrode bias is increased slowly over a period of 2 seconds. The typical radial current bifurcation of the biased $\mathrm{H}$-mode occurs after about 1 second. However, even prior to this, there is clear evidence that the density gradient in the plasma edge has local maxima where the radial derivative of $E_{\mathrm{r}}$ is maximum. These density gradient maxima become higher after the radial current bifurcation, since the $E_{\mathrm{r}}$ gradient increases further at that time. The fact that these maxima are seen even prior to the radial current bifurcation shows that it is the $E_{\mathrm{r}}$ change, not the current bifurcation itself, which leads to reduced transport. Changes in the fluctuation level $95,102,103$ and in the radial correlation of turbulence 95 have also been seen during direct biasing of the scrape off layer in a tokamak 95 and during direct biasing of the main plasma in a mirror machine. ${ }^{102,103}$ All of these results are consistent with $\mathrm{E} \times \mathrm{B}$ velocity shear causing changes in turbulence. 


\section{EXB VELOCITY SHEAR EFFECTS IN THE PLASMA CORE}

In addition to evidence of $\mathrm{E} \times \mathrm{B}$ velocity shear effects in the edge of $\mathrm{H}$-mode plasmas, there is also evidence that these effects are active in the core plasma in tokamaks. There is data here both from discharges in which the $\mathrm{E} \times \mathrm{B}$ shear effects appear to grow in from the $\mathrm{H}$-mode edge and in others in which the transport improves first near the magnetic axis. Most importantly, the evidence from the plasma core is also consistent with the $\mathrm{E} \times \mathrm{B}$ shear causing changes in turbulence and transport.

\section{A. VH-mode and high $\ell_{\mathbf{i}}$ discharges}

The VH-mode, an improved confinement $\mathrm{H}$-mode, has been identified on both DIII-D2,104-107 and JET. 2,108,109 A key feature of the VH-mode is the penetration of the $\mathrm{H}$-mode edge transport barrier deeper into the plasma. Although a magnetic configuration giving second stable ballooning access at the plasma edge facilitates formation of the $\mathrm{VH}$-mode, 2,108 it is clear from the experimental results that the region of improved confinement is much wider than the second stable region.106,107 Indeed, in DIII-D, 106,107 the width of the second stable region changes little between L-mode, $\mathrm{H}$-mode and VH-mode. The wider transport barrier in VH-mode occurs naturally at high power once the local bifurcation condition is satisfied. 30

Initial work on the VH-mode on DIII-D $106,107,110$ established a spatial and temporal correlation between the change in the $\mathrm{E} \times \mathrm{B}$ velocity shear and the change in local thermal transport. The region where the local thermal diffusivity changes most is between $\rho=0.6$ and 0.9 , which is the same region where the $\mathrm{E} \times \mathrm{B}$ velocity shear changes 
the most. This is also the region where density fluctuations, measured by FIR (far infra red) scattering, ${ }^{111,112}$ change the most. Furthermore, there is evidence 110 that the change in the $\mathrm{E} \times \mathrm{B}$ velocity begins 20 to $40 \mathrm{~ms}$ prior to the first change in thermal transport.

The high internal inductance $\left(\ell_{\mathfrak{i}}\right)$ discharges are created in DIII-D by starting with a nearly circular cross section discharge and ramping the vertical elongation from 1.3 to 2.2 in about $200 \mathrm{~ms}^{31}$ Since this time is short compared to the current diffusion time, the current density profile in the elongated plasma is transiently very peaked. Energy confinement improves by a factor of up to 1.8 relative to a discharge with the constant, higher elongation. A correlation has been seen between the increased $\mathrm{E} \times \mathrm{B}$ shear and the confinement improvement. 31

In order to test whether increased $\mathrm{E} \times \mathrm{B}$ velocity shear is causing improved confinement in VH-mode and high $\ell_{1}$ shots, magnetic braking of the plasma 113,114 was used to alter the toroidal plasma rotation and change the $\mathrm{E} \times \mathrm{B}$ velocity shear without changing the neutral beam input to the plasma. This means that the rotation can be changed without changing the other plasma parameters, giving a fairly clean test of causality. As is illustrated in Fig. 6, the experimental results3,4,114 are clearly consistent with the idea that changes in the ExB velocity shear cause the changes in local thermal transport. Transport rates increase in the region where the EXB shearing rate decreases, consistent with the theory. In addition, the density fluctuation amplitude increases when the transport increases. 3,112

When using magnetic braking to investigate the effects of $E \times B$ shear on confinement, one must take care that there are no direct effects of the nonaxisymmetric magnetic perturbation itself on transport. As has been discussed previously, 115 no direct effects are expected. That none occur is illustrated in Fig. 7. This figure shows that the stored 

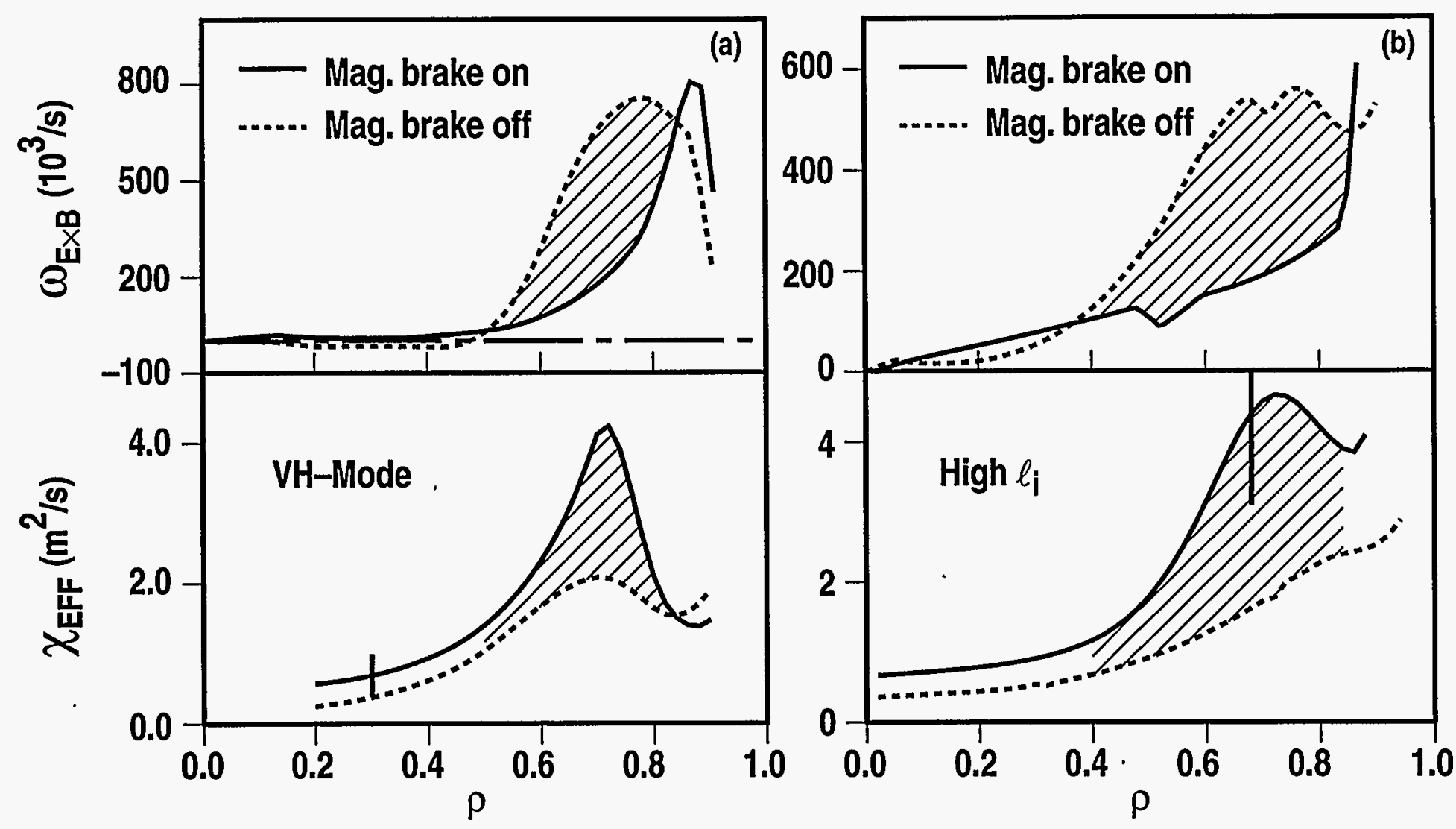

Fig. 6. Comparison of the change in the EXB shearing rate and the local single fluid thermal diffusivity inferred from power balance analysis in shots with and without magnetic braking. The magnetic braking was used to directly alter the ExB shearing rate. (a) VH-mode discharges with plasma conditions 1.3 MA plasma current, 1.7 T toroidal field, $4.7 \mathrm{MW}$ injected deuterium neutral beam power and $5.2 \times 10^{19} \mathrm{~m}^{-3}$ line averaged density. (b) elongation-ramp, high li discharges with plasma conditions 1.0 MA plasma current, 1.4 T toroidal field, $6.0 \mathrm{MW}$ injected deuterium neutral beam power and $6.0 \times 10^{19} \mathrm{~m}^{-3}$ line averaged density. At the times presented, all discharges are double null divertors operated in deuterium. 


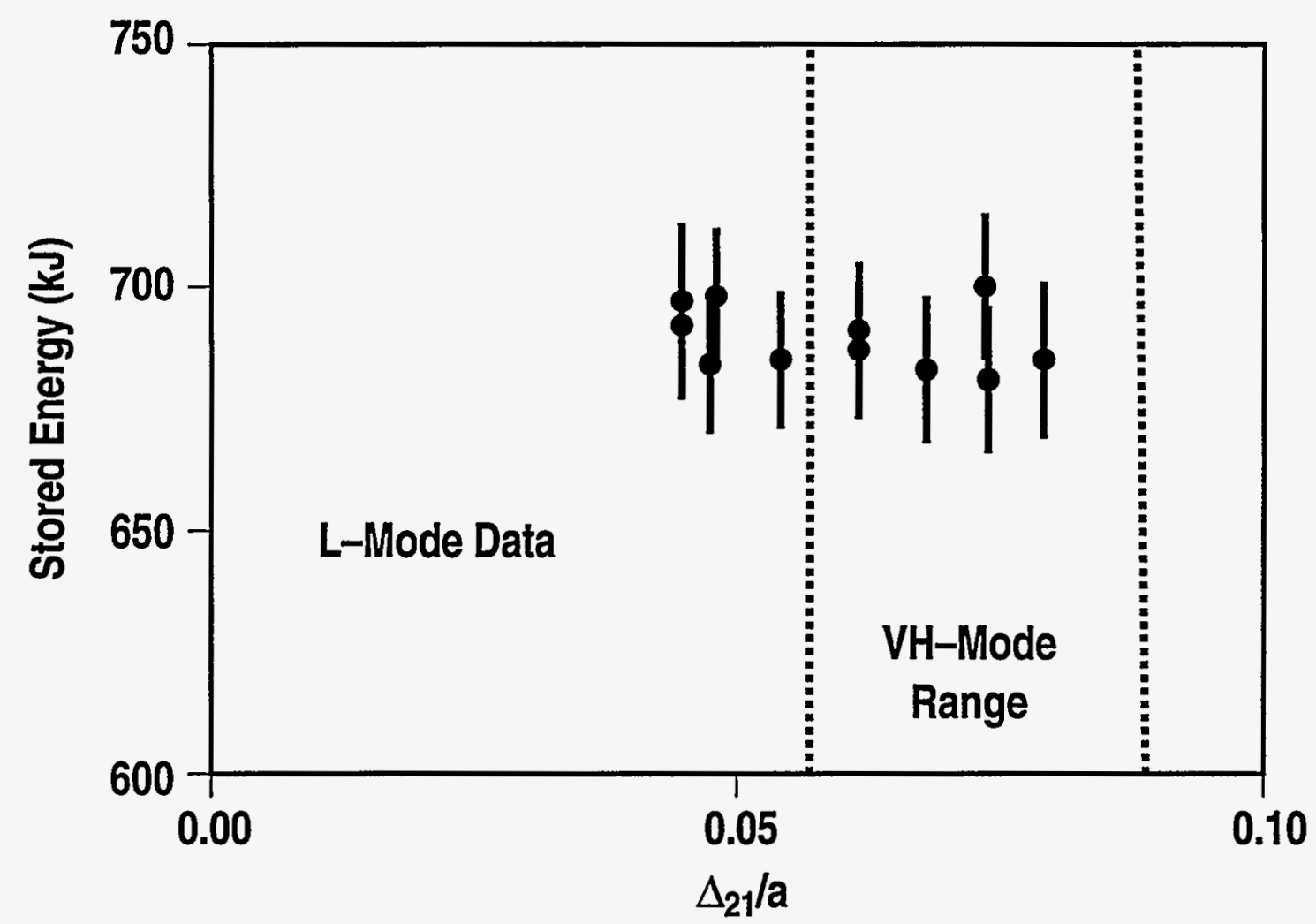

Fig. 7. Plot of the global stored energy in an L-mode plasma in DIII-D versus the amplitude of the nonaxisymmetric perturbation used to change toroidal rotation. Also shown on the figure is the range of the perturbation used in the $\mathrm{VH}$-mode experiment discussed in Fig. 6 . Note that the stored energy in L-mode is essentially unchanged over the range of amplitudes used, indicating no direct effect of the perturbation on confinement. Note also that the range of values covered on the $\mathrm{y}$-axis does not include zero. Plasma conditions are 1.8 T toroidal field, $6.9 \mathrm{MW}$ injected deuterium neutral beam power and $6.2 \times 10^{19} \mathrm{~m}^{-3}$ line averaged density. Results are from Ref. [116].

energy and, hence, the energy confinement time in L-mode divertor plasmas is essentially unchanged for the range of amplitudes of the magnetic braking used in the VH-mode experiment.116 No ExB velocity shear effects are expected in an L-mode plasma with this neutral beam input power, since the toroidal rotation and, hence, $E_{\mathrm{r}}$ are small. Any change in the energy confinement in the L-mode case is within the error bars of the measurement. These are much smaller than the $30 \%$ change in global confinement seen with magnetic braking for the data in Fig. 6.3 Accordingly, both the arguments presented previously 115 and the L-mode data in Fig. 7 are consistent with no direct effect of the nonaxisymmetric perturbation on transport. 


\section{B. Discharges with central transport barriers}

Over the past two years, the routine achievement of reduced transport in the central region of tokamak plasmas has generated enormous excitement in the field. Record fusion performance in DIII-D and JT-60U has been achieved utilizing these improved confinement discharges. 11,12 Although this routine achievement of improved confinement utilizes target plasmas with negative central magnetic shear, it appears that the key physics for the transport reduction is the $\mathrm{E} \times \mathrm{B}$ velocity shear.

Initial techniques for creating core transport barriers were restricted to narrow parameter ranges. ${ }^{117-120}$ Although it was not realized during the initial experiments, ${ }^{117}$ a common feature of these improved core confinement modes is profiles of the magnetic safety factor $q$ with $q>1$ on axis and low 121 or, in some cases 118,119 negative central magnetic shear. Routine achievement of core transport barriers required developing a means of shaping the current density profile. This development actually had two parts. First, experimentalists had developed the technique of heating the plasma during the initial current ramp ${ }^{122-124}$ or of a subsidiary current ramp ${ }^{125}$ as a technique for slowing current diffusion and broadening the q profile. Second, improvements in measurements of the magnetic field line pitch inside the plasma ${ }^{126-129}$ allowed them to rapidly and reliably determine the q-profile so that the response to this technique could be accurately determined. Heating during the initial current ramp is the technique used on most machines; $5,6,8,130-132$ off-axis current drive has also been used to produce 133,134 or sustain the negative central shear. ${ }^{135}$

As is illustrated in Fig. 8, impressively steep core gradients can be produced in these types of discharges. These lead to quite low inferred ion thermal diffusivities and particle diffusivities on most of the machines which have studied this mode of operation. $5-8,130,136-138$ On the other hand, the steepest core gradients are also 

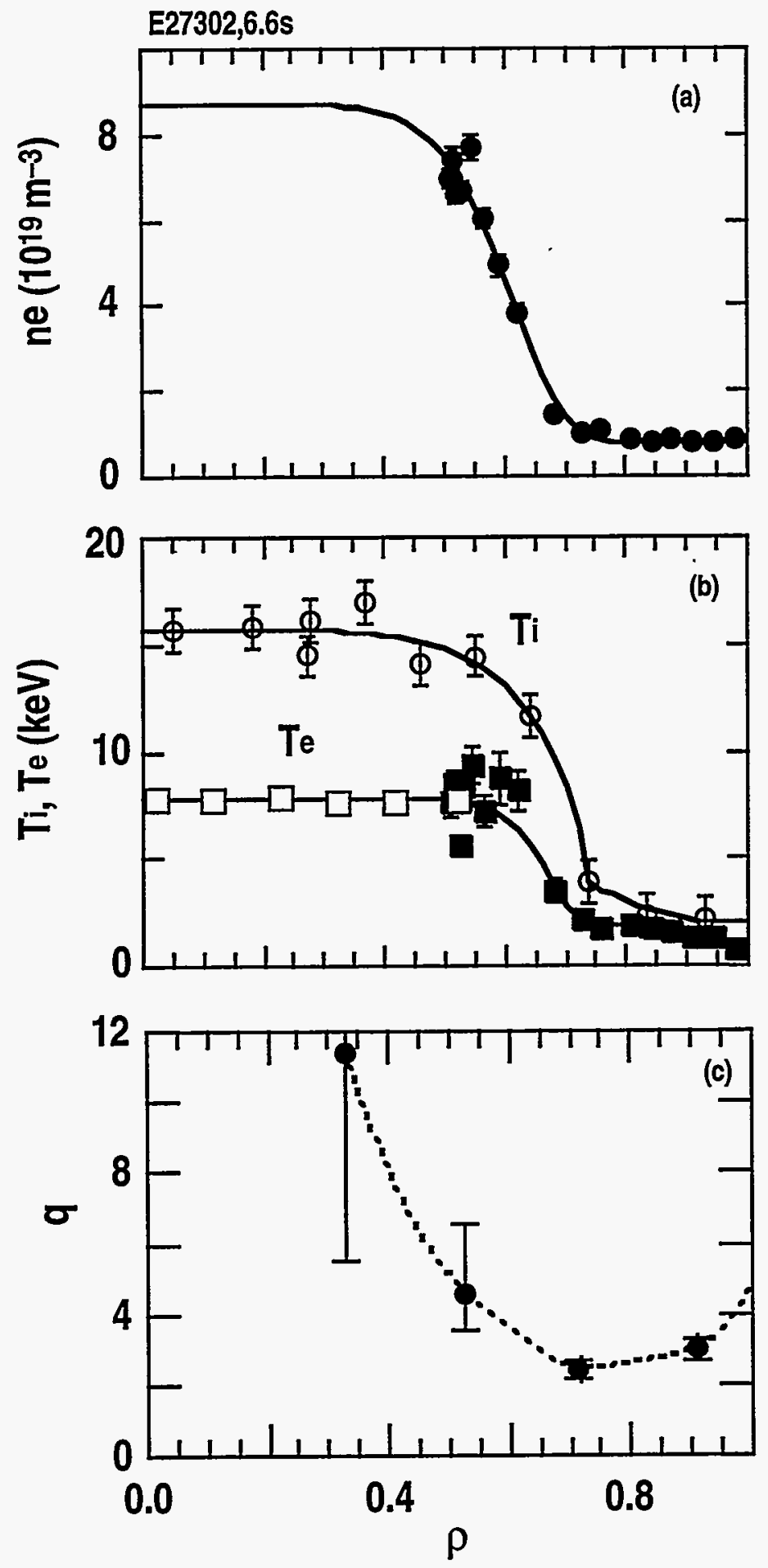

Fig. 8. Radial profiles for a high performance, negative central shear discharge in $J T-60 \mathrm{U}$. (a) Electron density $\mathrm{n}_{\mathrm{e}}$ measured by Thomson scattering. Solid curve is obtained by fitting interferometer data (one tangential and two vertical chords). (b) $T_{\mathrm{i}}$ from charge exchange recombination spectroscopy and $T_{\mathrm{e}}$. In the $T_{\mathrm{e}}$ profile, closed points are measured by Thomson scattering and open points are by electron cyclotron emission. (c) q profile from motional Stark effect measurements. Data from Ref. [137]. 
associated with MHD stability problems; 136,137 the best compromise appears to be shots where the gradient scale lengths are never as locally steep, but where transport is reduced across the whole plasma. 11

The model which has evolved to understand these results in the negative magnetic shear discharges includes synergistic effects of magnetic shear and $E \times B$ velocity shear. The negative or low magnetic shear allows stabilization of high $\mathrm{n}$ MHD modes (e.g. ballooning modes). In addition, the magnetic configuration with $q>1$ everywhere stabilizes sawtooth MHD oscillations. Lack of these instabilities plus application of additional heat and, possibly, angular momentum input allows pressure and toroidal rotation gradients to build, thus starting the feedback process discussed with Eq. (1). A local transport bifurcation can occur based on $\mathrm{E} \times \mathrm{B}$ shear decorrelation of turbulence as discussed by Staebler and Hinton. 29,30 As pointed out by Diamond et al., 27,28 the local transport bifurcation starts first in the plasma core because magnetic shear effects, $T_{\mathrm{i}} / T_{\mathrm{e}}>1$ and the Shafranov shift all give the lowest threshold (microinstability growth rate) there. The transport barrier propagates outward into the region of increased microinstability growth rate until the local $\mathrm{E} \times \mathrm{B}$ shearing rate can no longer overcome the instability growth rate. Because $E_{\mathrm{r}}$ can be influenced by particle, angular momentum and heat input [see Eq. (1)], various of these terms can be active in various machines. In TFTR, for example, the pressure gradient term is dominant and $E_{\mathrm{r}}<0$ in the plasma core $^{139}$ while the toroidal rotation term is dominant and, as is shown in Fig. 4, $E_{\mathrm{r}}>0$ in the plasma core in DII-D.

There are a number of testable predictions which this theory makes:

1. Sawteeth and ballooning modes are turned off by the $q$ value and profile shape.

2. Negative magnetic shear alone is not sufficient for transport barrier formation. 
3. The theory is a local bifurcation theory, accordingly, there should be spatial and temporal correlation between increased $\mathrm{E} \times \mathrm{B}$ shearing rate, transport reduction and fluctuation decrease.

4. $\omega_{\mathrm{E} \times \mathrm{B}}$ should be comparable to $\gamma_{\mathrm{MAX}}$ before barrier formation and should increase more than $\gamma_{\text {MAX }}$ after formation.

5. As can be seen in Eq. (3), the $\left(R B_{\theta}\right)^{2} / B$ factor will make $\omega_{E \times B}$ bigger on the low toroidal field side of a flux surface, especially in cases with large Shafranov shift; accordingly, turbulence stabilization is easier there and harder on the high toroidal field side.

6. Since the theory contains a local transport bifurcation when $\omega_{\mathrm{E} \times \mathrm{B}}$ is big enough, there must be a threshold in the heat, particle or angular momentum input required to create the transport barrier. This has four corollaries. First, it is the amount of input inside a given flux surface which matters, not the total power. Second, since the source has to drive pressure gradients and/or rotation, the source strength required must increase at least linearly with the local density. Third, the barrier should expand from the inside out when the source is increased and contract from the outside in when it is decreased. Fourth, destruction of the ExB velocity shear by changing the momentum input should lead to barrier collapse even at constant input power.

7. Hot ion modes should be favorable for barrier formation, since many of the key unstable modes in the plasma core (e.g. collisionless trapped electron modes and ion temperature gradient modes) are stabilized by increasing $\mathrm{T}_{\mathrm{i}} / \mathrm{T}_{\mathrm{e}}$. 
Consider first the experimental evidence for the effects of the $q$ profile. The importance of having discharges without sawteeth is clear in the case of the high $\beta_{\mathrm{p}}$ mode in JT-60U; 120,121 the improved core confinement does not happen in sawtoothing discharges. The negative magnetic shear configuration also removes the limits imposed by ballooning modes, as is shown in DIII- $\mathrm{D}^{5}$ and TFTR 130 where the measured pressure profiles are shown to be in the second stable ballooning mode regime.

Although the q profile plays a role in achieving the core confinement improvement, there is considerable evidence that, even with the proper $q$ profile, some other factor is needed to create the confinement improvement. Some of the clearest evidence comes from the comparison of RS (Reverse Shear) and ERS (Enhanced Reverse Shear) transition data in TFTR. 7 The transition between the RS (unimproved confinement) and the ERS (improved confinement) states has the nature of a bifurcation. As is shown in Fig. 9, at the time of the bifurcation, the q-profiles in the two discharges are essentially identical. This indicates that some other factor is needed to explain the transition. The difference is the time evolution of $\omega_{\mathrm{E} \times \mathrm{B}}$. Other evidence is also consistent with this conclusion. If negative magnetic shear were the only factor needed for the transport reduction, then all negative magnetic shear discharges should exhibit improved confinement during the current ramp phase when the magnetic shear reversal is even stronger. However, except for some observations of slow confinement improvements during this phase on DIII-D, 140 most machines report no confinement improvement until the high power phase is reached. $130-132$

Additional evidence that negative magnetic shear is not the key factor in core transport barrier formation comes from high $\beta_{\mathrm{p}}$ mode discharges in JT-60U.141 Core particle and ion thermal transport barriers can be formed even in discharges with positive 

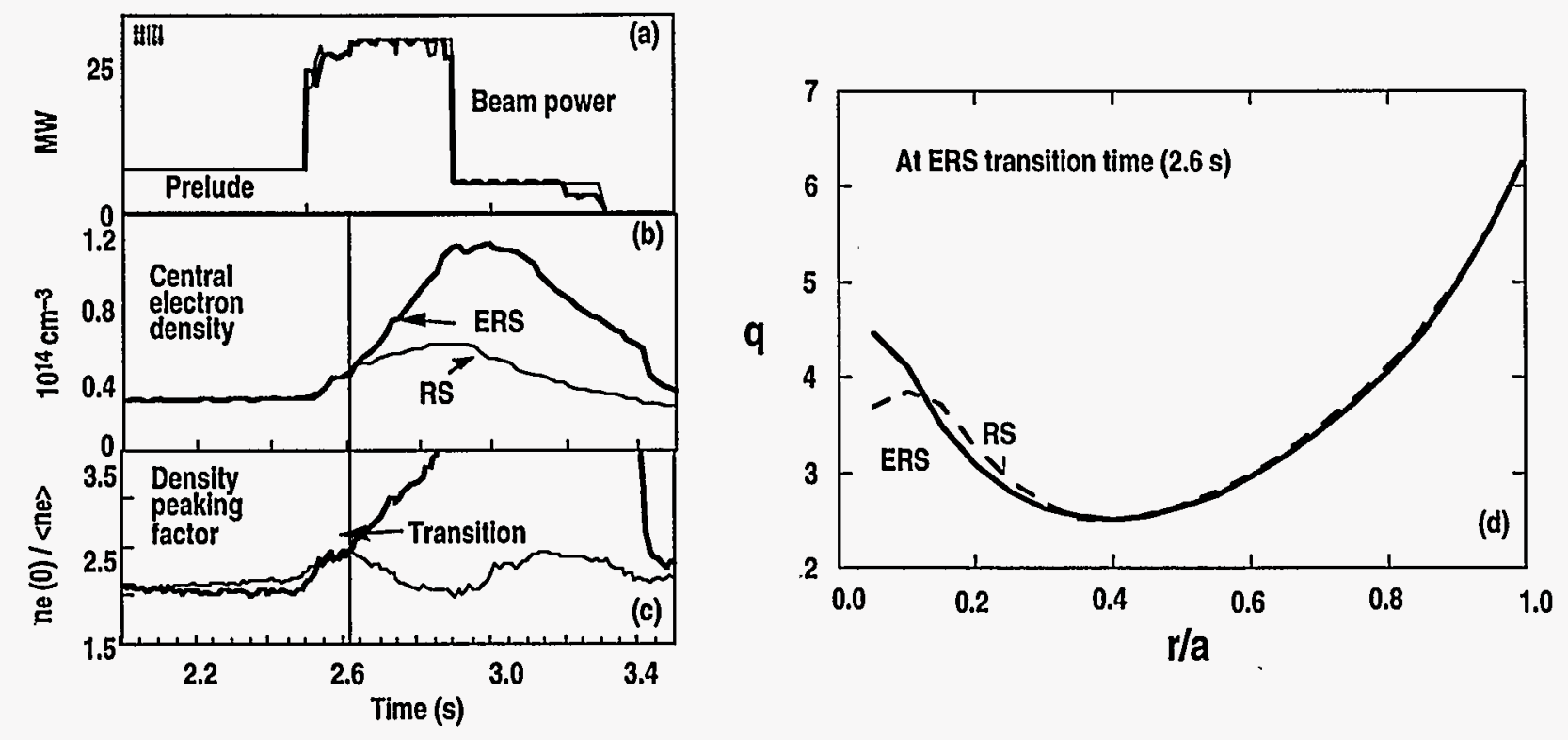

Fig. 9. Plots from two discharges in TFTR showing that the q-profile is identical at the time of the RS-ERS transition. (a) Deuterium neutral beam input power, (b) central electron density, (c) density peaking factor all plotted as a function of time. (d) q-profile at the time of the transition. The RS plasma traces are the dashed lines. Data from Ref. I71. 
magnetic shear, ${ }^{141}$ although, as mentioned previously, sawtooth-free discharges are required. 120,121

Spatial and temporal correlation between increased $\mathrm{E} \times \mathrm{B}$ velocity shear, turbulence reduction and transport reduction has been established on DIII-D6,11,140,142 and TFTR.7,139,143-145 The spatial correlation is illustrated in Figs. 10 and 11, which shows that the low turbulence level determined by reflectometry in the core of an ERS discharge exists in the same region where the $\mathrm{E} \times \mathrm{B}$ shearing rate is increased and the transport decreased over the comparable RS case.

There is also a significant amount of data from DIII-D $6,140,142,146$ and TFTR 7,139,143-145 showing that $\omega_{\mathrm{E} \times \mathrm{B}}$ is comparable to $\gamma_{\mathrm{MAX}}$ prior to the formation of the transport barrier and significantly exceeds it after formation. An example of the DIII-D data is shown in Fig. 12; some of the TFTR results are in Fig. 11. An important feature to notice in both Figs. 11 and 12 is that the $\gamma_{\text {MAX values actually increase in the }}$ reduced transport phase over a significant portion of the region where the transport reduction occurs. This is not surprising, since the gradients which drive the turbulence have increased. However, this increase indicates that the fluctuation and transport reduction are not caused by stabilization of the turbulence by any of the factors which are included in the $\gamma_{\mathrm{MAX}}$ calculation. Accordingly, although other factors (e.g $T_{\mathrm{i}} / T_{\mathrm{e}}>1$, Shafranov shift, etc.) may help to reduce $\gamma_{\mathrm{MAX}}$ initially so that the $\mathrm{E} \times \mathrm{B}$ shearing rate can exceed the growth rate, they themselves are not sufficient to explain the reduced fluctuations and transport.

The poloidal variation of $\omega_{\mathrm{E} \times \mathrm{B}}$ and its correlation with turbulence are shown in Fig. 13. In this particular shot, the large Shafranov shift gives a variation in the $\left(R B_{\theta}\right)^{2} / B$ factor in Eq. (3) of about a factor of seven between the high and low field sides of a given flux surface. This produces the distinct in-out asymmetry in $\omega_{\mathrm{E} \times \mathrm{B}}$ seen in Fig. 13. Also 


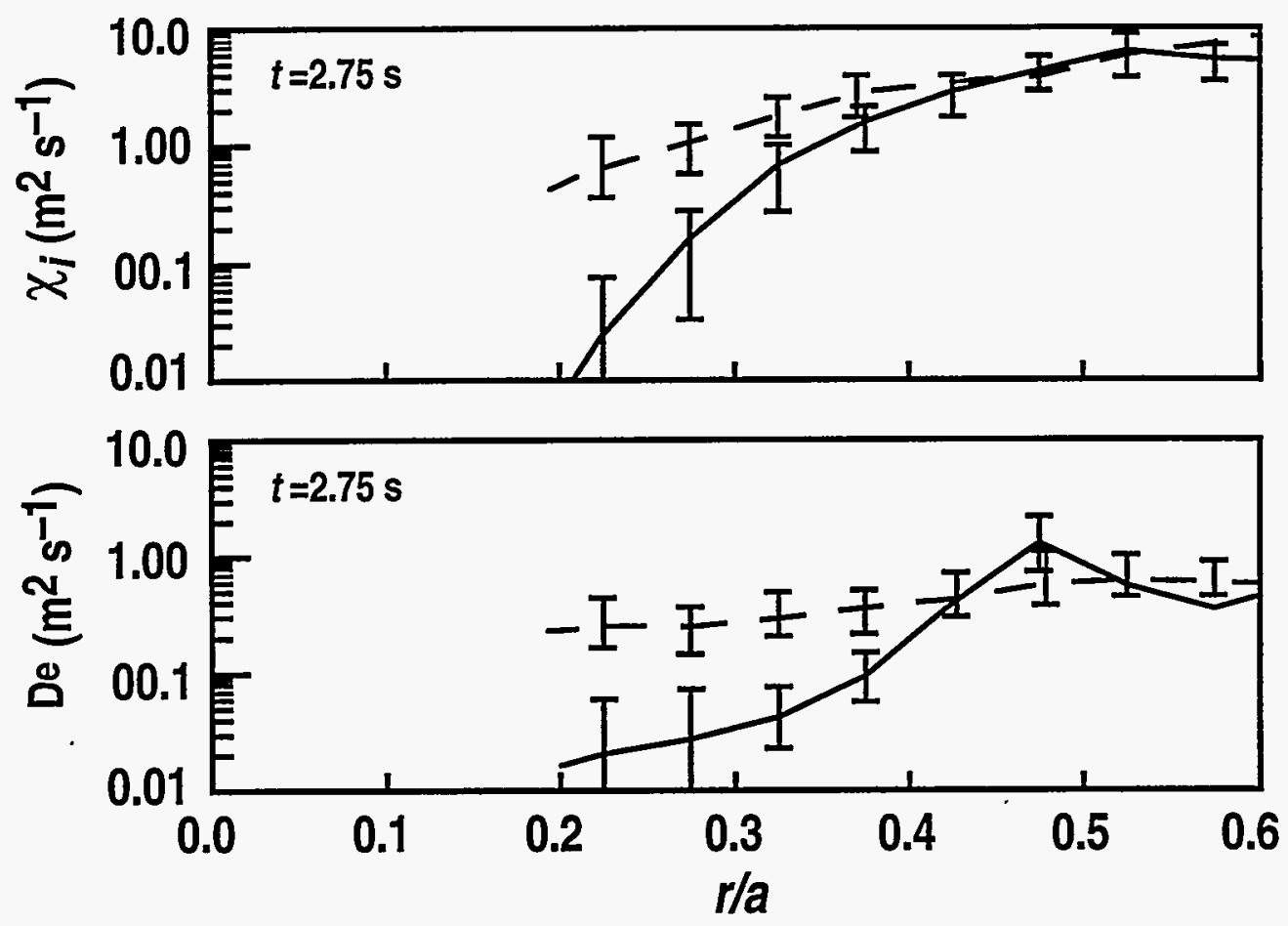

Fig. 10. Plots of electron particle diffusivity $\left(D_{\mathrm{e}}\right)$ and ion thermal diffusivity in the ERS (solid line) and the RS plasmas of Figs. 9 and 11 at $t=2.75$ s into the two discharges. Data from Ref. [7].

shown in Fig. 13 is the scattered power from an FIR scattering system. ${ }^{96}$ The distinct inout asymmetry in the turbulence near the end of the high performance phase in this shot is qualitatively consistent with the much reduced $\mathrm{E} \times \mathrm{B}$ shearing rate on the high toroidal field side of the flux surfaces relative to the low toroidal field side, as is shown in Fig. 13. Poloidally, these modes clearly have the largest amplitude in the region where $\omega_{\mathrm{E} \times \mathrm{B}}$ is the smallest.

The power threshold observations are also consistent with the idea of $\mathrm{E} \times \mathrm{B}$ shear stabilization. In order for the transport bifurcation process to first start, gradients and rotation must be big enough to produce the required $\mathrm{E} \times \mathrm{B}$ shear. A power threshold for the formation of the core transport barrier is seen on most machines. $6,120,130$ Experiments on JT-60U ${ }^{147}$ show that it is the power inside a given flux surface that is essential for creating the core barrier in the high $\beta_{\mathrm{p}}$ mode. In the experiment shown in 

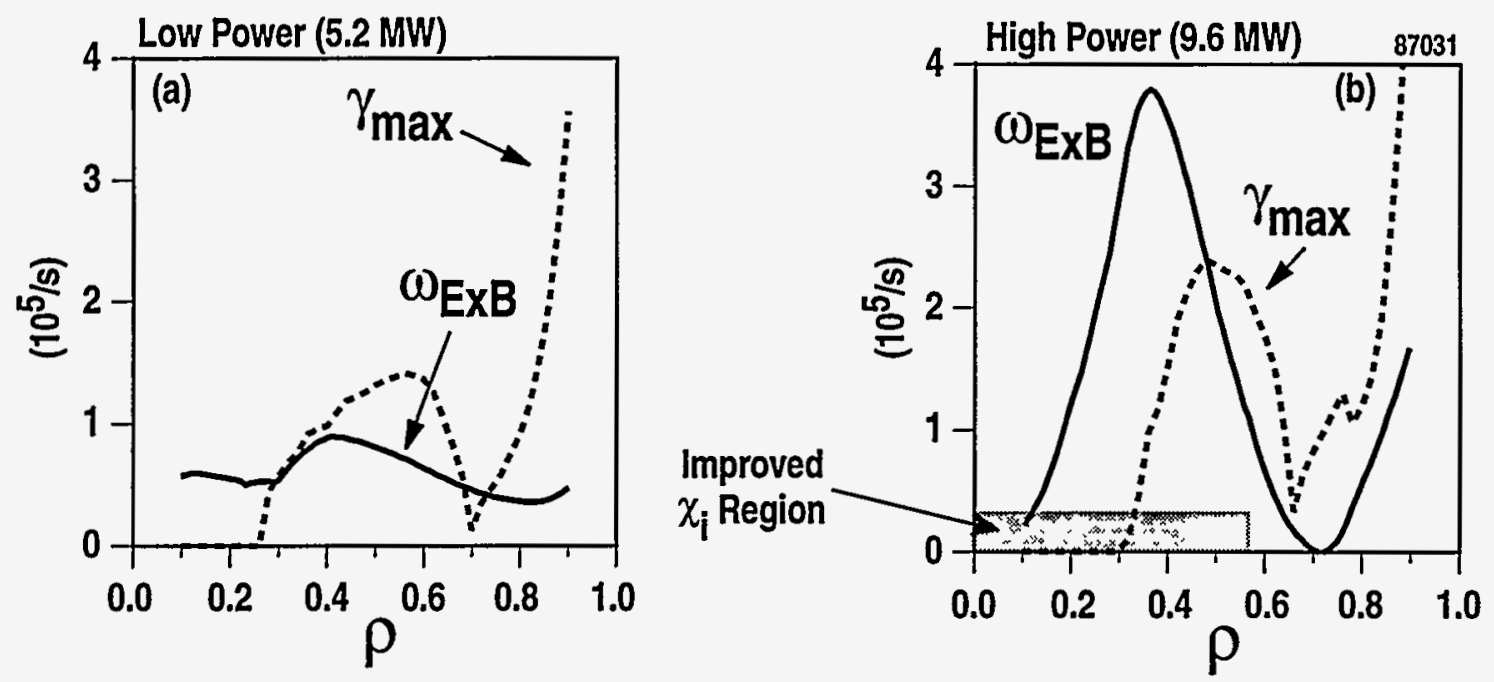

Fig. 12. Plots of the ExB shearing rate and the maximum turbulence growth rate for two times in a negative central magnetic shear shot on DIII-D (87031). (a) During the early formation of the transport barrier in the plasma core, the $\mathrm{E} \times \mathrm{B}$ shearing rate equals or exceeds the turbulence growth rate over only a small region in the center of the plasma. (b) During the later, higher input power phase, the ExB shearing rate has increased so that it exceeds the turbulence growth rate over a much wider region. As is indicated on the plot, this is the region over which transport has been reduced. Plasma conditions are 1.6 MA plasma current and 2.1 T toroidal field for both cases. In (a) there is $5.2 \mathrm{MW}$ injected deuterium neutral beam input power and $2.0 \times 10^{19} \mathrm{~m}^{-3}$ line averaged density while for (b) the corresponding figures are $9.6 \mathrm{MW}$ and $2.4 \times 10^{19} \mathrm{~m}^{-3}$. Results are from Ref. [146].

momentum confinement times do not increase faster than linearly with the density. Since energy and angular momentum confinement in tokamaks depends, at best, weakly on density, the form for the pressure gradient and rotation contributions to $E_{\mathrm{r}}$ in Eq. (1) shows that $E_{\mathrm{r}}$ should decrease as $1 / \mathrm{n}_{\mathbf{j}}$ when the power and angular momentum input are constant. This is because the pressure gradient term has $1 / n_{i}$ as a coefficient and because the rotation speed is proportional to $1 / \mathrm{n}_{\mathrm{i}}$ at constant angular momentum content. In addition, if increasing density diminishes the local input near the axis, the same effect as shown in Fig. 14 could play a role. A power threshold increasing with plasma density has been seen in the high $\beta_{\mathrm{p}}$ mode in JT-60U.148,149 As is shown in Fig. 15, the threshold power for the creation of the core transport barrier in high $\beta_{\mathrm{p}}$ discharges increases faster than linearly with the plasma density. High $\beta_{p}$ mode is perhaps one of the best cases to check the intrinsic density scaling, since it does not require negative 


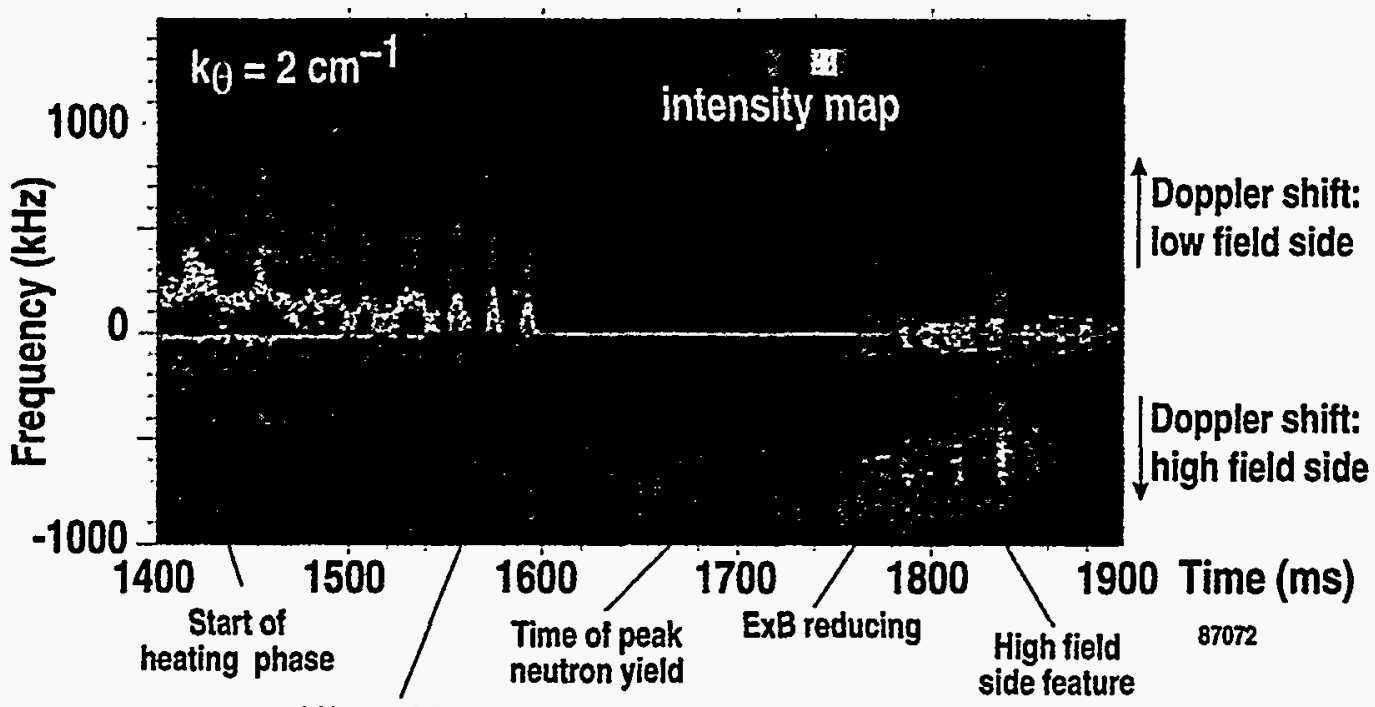

LH transition

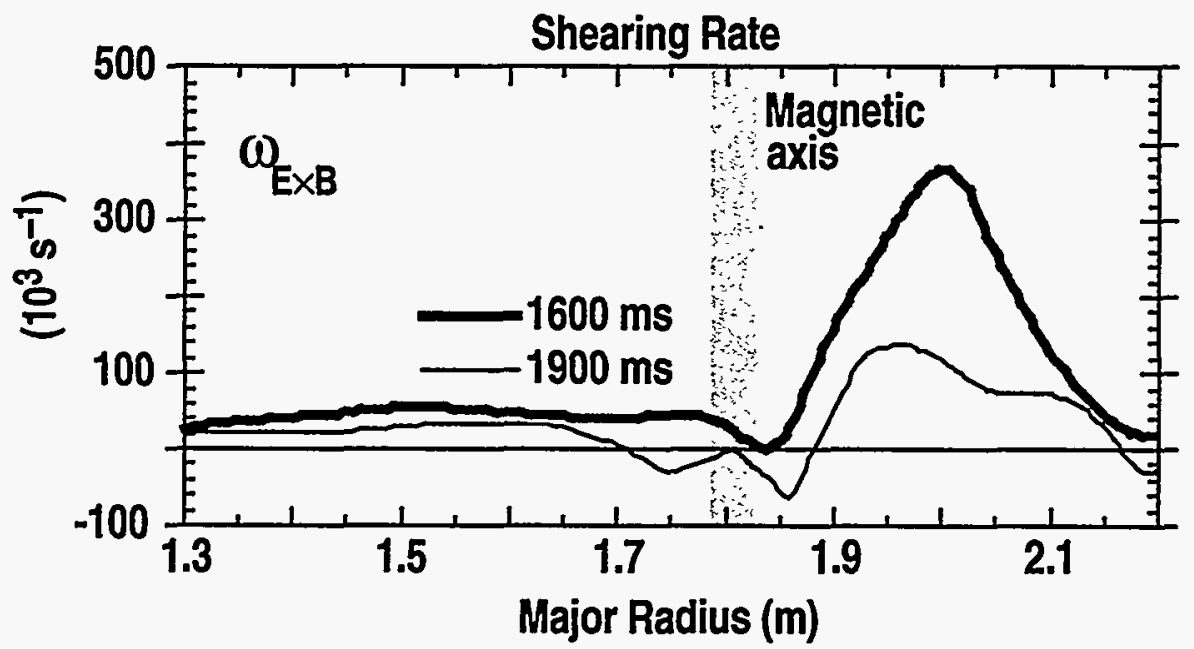

Fig. 13. Upper plot shows the scattered signal from the DIII-D far infra-red scattering system for a shot with a negative central shear core transport barrier. Lower plot shows $\omega_{E \times B}$ from Eq. (3) for two different time during this shot. Because of the EXB Doppler shift of the FIR signals, the more negative frequency side of the upper plot corresponds to the core plasma region inside the magnetic axis, the more positive frequency side corresponds to the core region outside the magnetic axis while the portion near zero frequency is an overlap of the signals from the near the plasma edge and the magnetic axis. Note that most of the turbulence is quenched near $160.0 \mathrm{~ms}$, at the time of the $\mathrm{L}$ to $\mathrm{H}$ transition, indicating that this portion the signal came from near the plasma edge. Small, bursting turbulence is left only on the negative frequency side, which corresponds to the portion of the plasma inside the magnetic axis. As the plasma approaches the peak performance phase, this high-field-side turbulence increases first before there is any sign of activity on the low field side.

magnetic shear for its formation. Accordingly, the change in current penetration that occurs when higher density lowers the plasma temperature should not play a major role. 

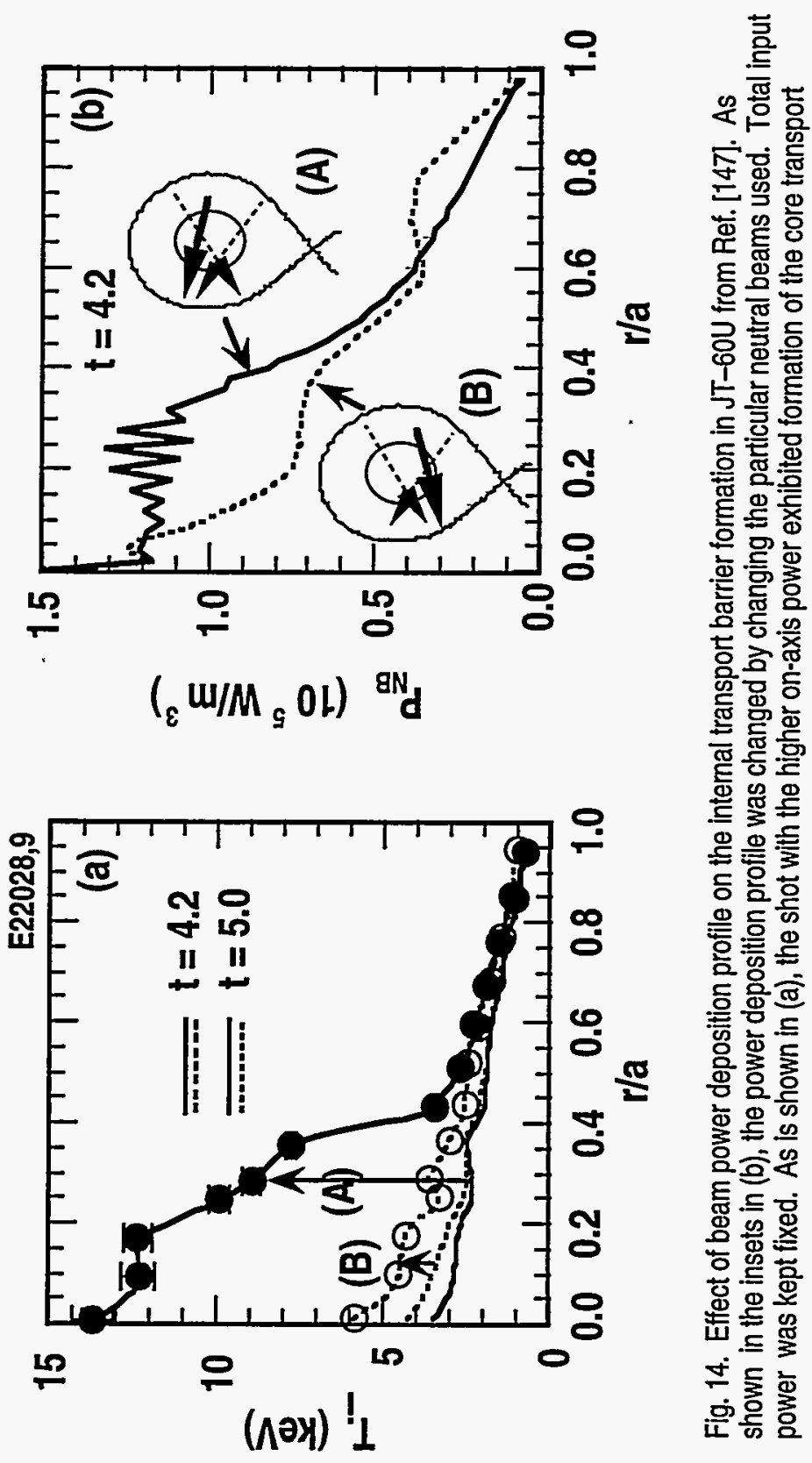


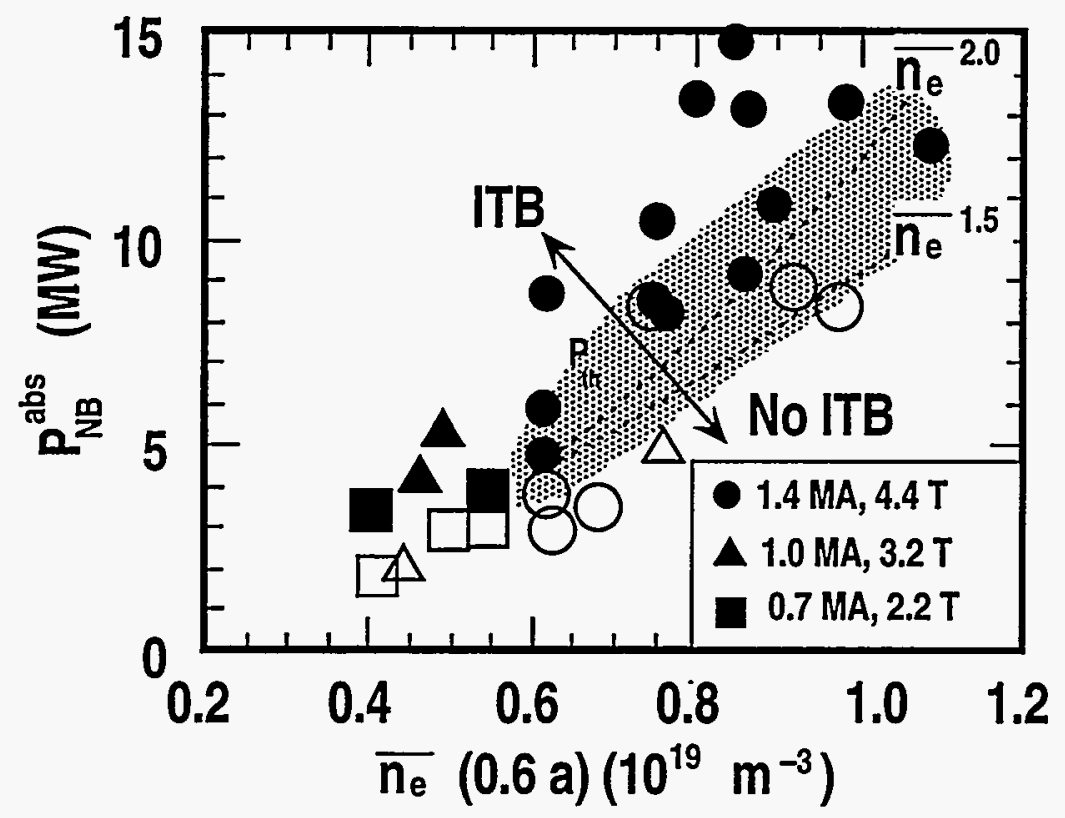

Fig. 15. Change of power input needed for core transport barrier formation with plasma line averaged density for $\mathrm{JT}-60 \mathrm{U}$ high $\beta_{p}$ mode discharges. Figure is from Ref. [149].

Barrier expansion and contraction with changing input power has been studied in DIII-D. As can be seen in Fig. 16, the transport barrier expands from the middle outwards when the power is stepped up. This agrees with the expectation from the EXB shear stabilization model that the core barrier forms first near the axis and then, as the $\mathrm{E} \times \mathrm{B}$ shear increases, can move out into regions where $\gamma_{\mathrm{MAX}}$ is greater. The inverse process is seen to happen when the power is stepped down. As can be seen in Figs. 11 and 12, the ExB shearing rate is well above $\gamma_{\mathrm{MAX}}$ further into the core, so it takes a bigger decrease before $\omega_{E} \times B$ reaches the marginal point. Accordingly, the transport barrier is destroyed in the outer regions first, where the plasma is closer to marginal stability. Transport analysis of this shot ${ }^{140}$ supports this interpretation of the raw temperature and rotation data shown in Fig. 16.

Recently, a key test of causality has been performed on TFTR.139,143-145 As is illustrated in Fig. 17, this experiment studied the collapse of the core transport barrier in 


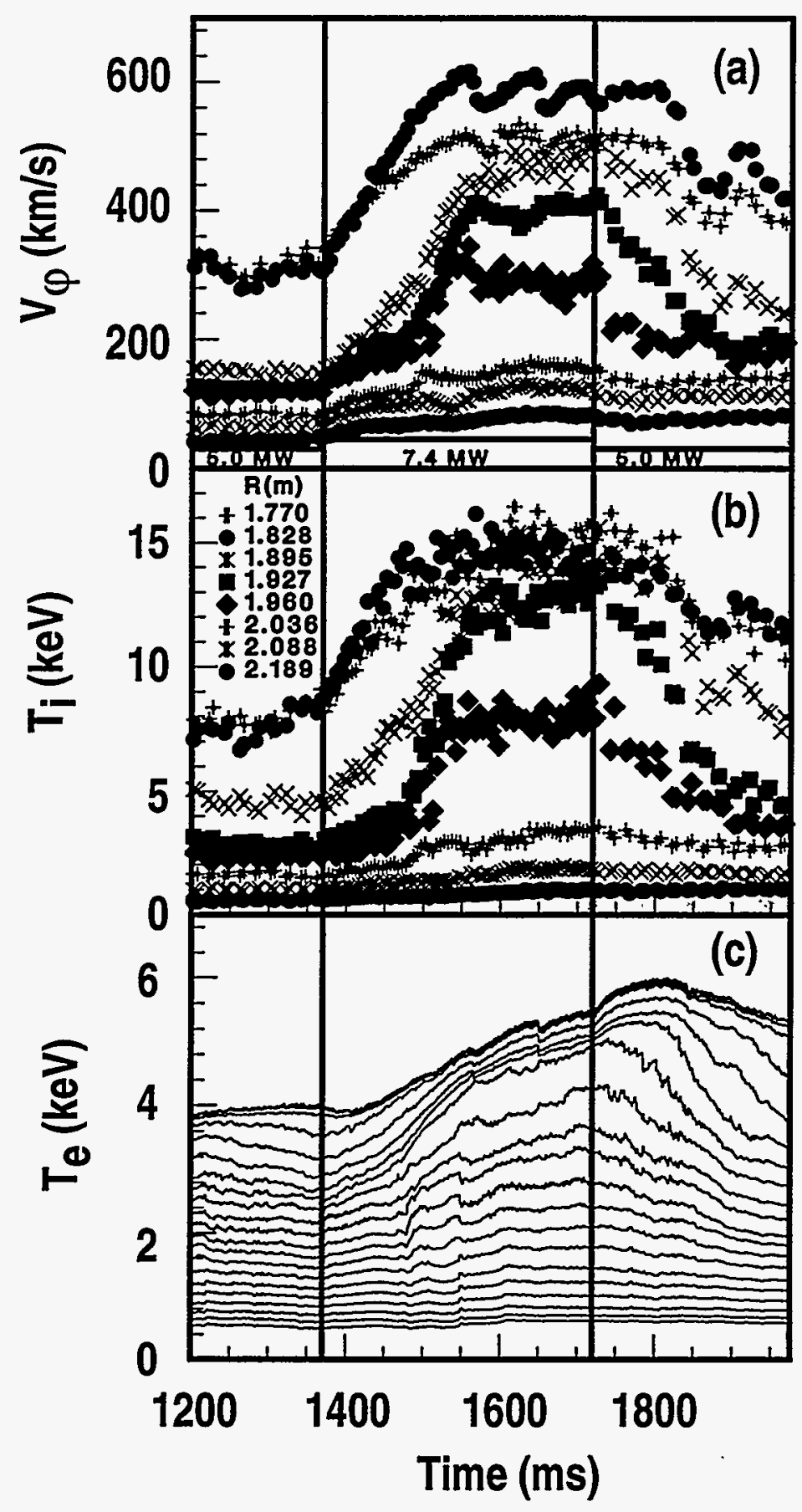

Fig. 16. Expansion and contraction of a core transport barrier in DIII-D due to changes in the neutral beam input power. (a) Toroidal rotation of C IV ions from charge exchange recombination spectroscopy; (b) ion temperature at the locations shown, and (c) electron temperature from electron cyclotron emission. The electron temperature measurements are spaced $2.5 \mathrm{~cm}$ apart in major radius. After the beam power shown in (a) is stepped up, the centermost ion temperatures and toroidal rotation respond immediately but there is a time delay for the outer locations to manifest the improved confinement, indicating the time it takes for the transport barrier to expand. Improve confinement is indicated by the change in slope of the curves. The inverse process happens when the power is stepped down; the temperature and rotation further out in the plasma respond first. 

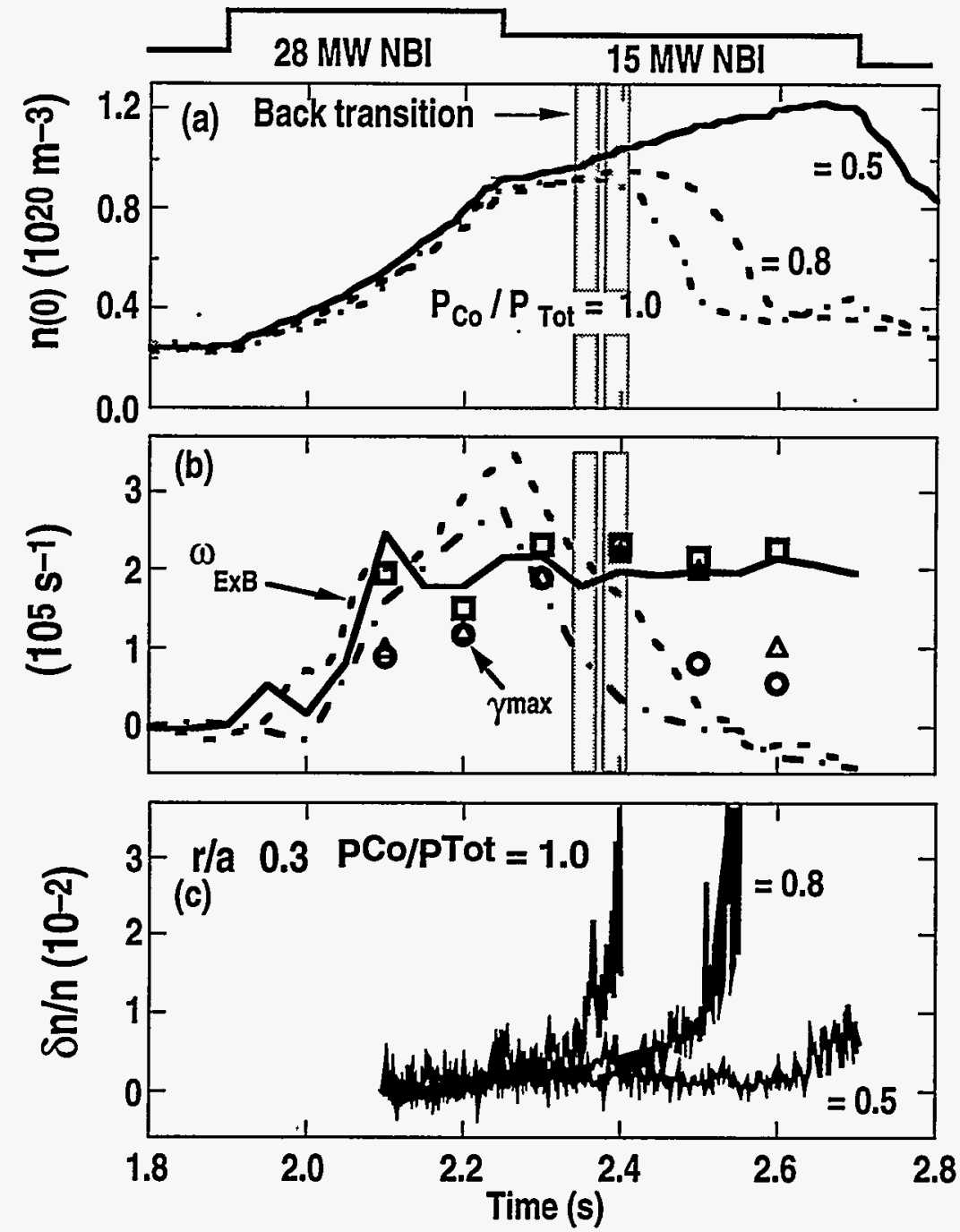

Fig. 17. Plot showing variation of time of back transition in postlude phase of a set of ERS shots in TFTR. (a) central density versus time for different fractions of power from the co-injected neutral beams showing that the back transition is earlier for greater coinjection. (b) ExB shearing rate and maximum turbulence growth rate for the same shots; turbulence growth rates are the open symbols; notice that the $E \times B$ shearing rate begins to change before the density in (a) shows that the transport barrier collapses. (c) density fluctuation amplitude from reflectometry showing that the density fluctuations increase when the transport barrier collapses.

the lower power, postlude phase. The beam power was stepped down from the peak $28 \mathrm{MW}$ used to form the barrier to $14 \mathrm{MW}$. During the $14 \mathrm{MW}$ phase, the angular momentum input to the plasma was changed by changing the fraction of the beam power which came from neutral beams injecting parallel to (co) and anti-parallel to (counter) the plasma current. This allowed the experimenters to directly change the toroidal rotation. 
Since the $E_{\mathrm{r}}$ in the ERS phase is negative 139,145 and since a co-rotation of the plasma contributes a positive $E_{\mathrm{r}}$ according to Eq. (1), it was possible to change the $\mathrm{E} \times \mathrm{B}$ shear in the plasma without changing the total input power. Accordingly, it was possible to change the ExB shear without changing many of the other quantities which contribute to

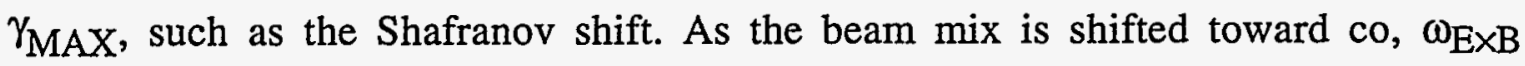
decreases more quickly and the back transition occurs sooner. In addition, as is shown in Fig. 17, the fluctuations measured by reflectometry 143 grow back up at the same time that the density trace indicates that the transport barrier is being destroyed. Transport analysis 139,145 shows that the transport rates increase at the same time that the fluctuations return. Accordingly, there is a clear temporal correlation between the decrease in $\omega_{E \times B}$, the increase in the fluctuations and the increase in transport. In this case, as in the VH-mode and high $\ell_{\mathrm{i}}$ magnetic braking, the experimenters have directly changed the EXB shearing rate. These results, then, are a strong test of causality and are consistent with $\mathrm{E} \times \mathrm{B}$ velocity shear causing the suppression of turbulence and transport.

Comparison of the TFTR and DIII-D results shows how the EXB shear stabilization hypothesis can unify the experimental results. The toroidal rotation profiles in the TFTR balanced injection cases are very different than those in the DIII-D co-injection cases. Had one tried to explain the core barrier formation in the two machines through shear in the toroidal rotation speed, the TFTR cases would have been incomprehensible, since the toroidal rotation is essentially zero. However, when considered from the standpoint of sheared $\mathrm{E} \times \mathrm{B}$ flow, the results from both machines are clearly part of the same basic physics. 
Finally, there has been no systematic study of the role of the $T_{\mathrm{i}} / T_{\mathrm{e}}$ ratio in core transport barrier creation. Most experiments have worked in the hot ion mode. $5-8,130$ 132,135-149 However, it is possible to create a core transport barrier in cases with almost equal $T_{\mathrm{i}}$ and $T_{\mathrm{e} .} 150$

Although a considerable amount of the data on core transport barriers is consistent with the $\mathrm{E} \times \mathrm{B}$ velocity shear decorrelation hypothesis, there are still at least two outstanding puzzles. First, there is the puzzle of the lack of change in electron thermal transport in some machines. Both JT-60U 137,138 and Tore Supra ${ }^{134}$ see significant reduction in the electron thermal diffusivity in the core transport barrier region under cases of negative central shear. However, JT-60U sees no significant change in the electron thermal diffusivity in the high $\beta_{\mathrm{p}}$ mode, which has almost no magnetic shear in the plasma core. 115 DII-D sees modest changes in electron thermal diffusivity in some cases $^{6}$ and large changes in others 140 while TFTR sees little if any change. 130 A naive model in which one thought of complete turbulence suppression would predict large changes in all cases. However, the experimental results show that turbulence is reduced but not completely suppressed. 7,11 This variability in the electron thermal transport reduction indicates that there is still something to learn about $E \times B$ velocity shear effects on the electron transport channel.

A second result provides a cautionary note about trusting the $\omega_{\mathrm{E} \times \mathrm{B}}=\gamma_{\mathrm{MAX}}$ stabilization criterion too exactly. As is shown in Fig. 18, formation of the ERS mode in TFTR can occur at values of $\omega_{\mathrm{E} \times \mathrm{B}}$ as much as a factor of three below $\gamma_{\mathrm{MAX}}$. This range of values is similar to the range seen in the gyro Landau fluid calculation. 18 The fact that there is this range indicates a need for improved theory in this area. 


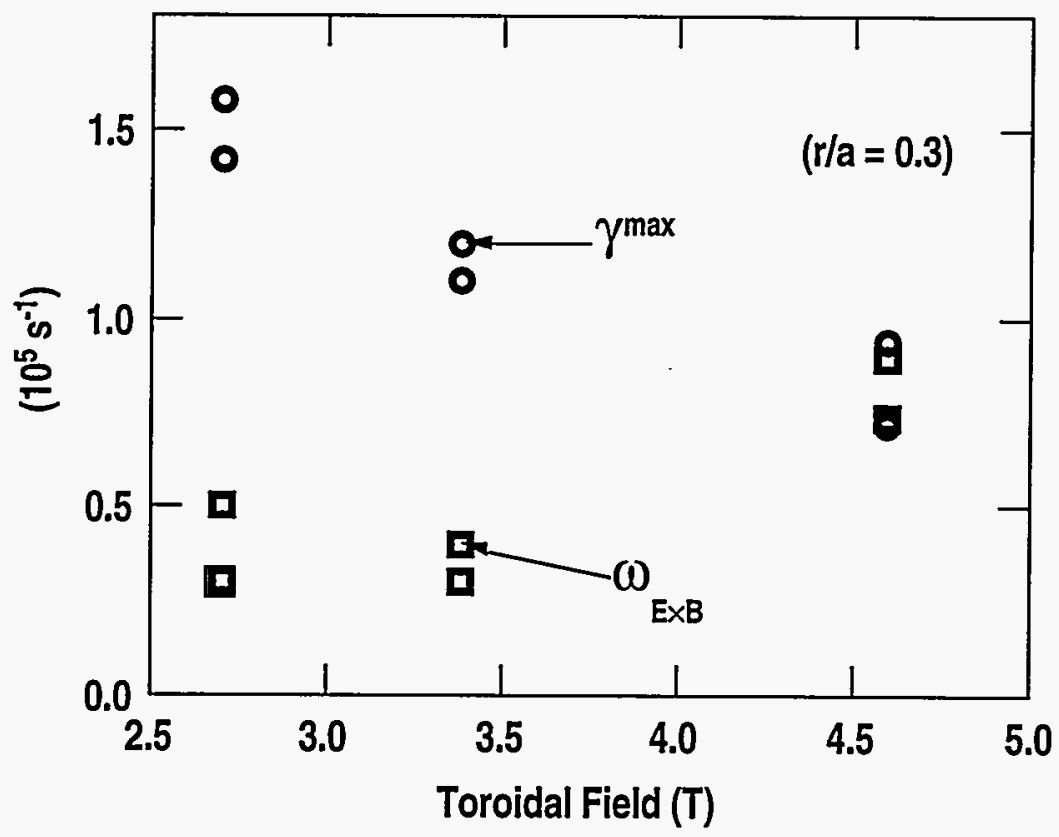

Fig. 18. Linear growth rates (circles) and ExB shearing rates (squares) for various toroidal magnetic fields at the time of formation of the ERS core transport barrier on TFTR. ${ }^{144}$ This scan is done at constant q; hence, plasma current is varying in proportion to toroidal field. At low toroidal field, the EXB shearing rate needed to stabilize turbulence is only about $1 / 3$ of the linear growth rate. 


\section{TRANSPORT REDUCTION ACROSS THE WHOLE PLASMA}

Most of the devices discussed in Section IV, have achieved particle and ion thermal diffusivities that are at or below standard neoclassical values in the plasma core. In addition, $\mathrm{H}$-mode plasmas discussed in Section III have significant transport reduction in the plasma edge. A key question is whether the $\mathrm{H}$-mode edge confinement improvement and the core confinement improvement can be combined to yield reduced transport across the whole plasma radius. Two devices have achieved results like this. In JT-60U, the high $\beta_{\mathrm{p}} \mathrm{H}$-mode discharges ${ }^{147-149}$ start out with the high $\beta_{\mathrm{p}}$ mode core transport barrier and then acquire an $\mathrm{H}$-mode edge transport barrier later in the shot. In DIII-D controlled manipulation of the time of the $\mathrm{L}$ to $\mathrm{H}$ transition yields discharges with ion thermal diffusivity at the standard neoclassical value across the whole minor radius. ${ }^{11}$ This is accompanied by significant reduction in the density fluctuations across the whole plasma. ${ }^{11,142}$ As is shown in Fig. 19, the ExB shearing rate significantly exceeds the linear growth rate across the whole plasma in another DIII-D discharge where the ion thermal diffusivity is at or below standard neoclassical across the whole minor radius. 6 Indeed, in these sorts of discharges, the term transport barrier is a bit of a misnomer, since the transport is reduced throughout the plasma and the radial profiles show no sign of a local barrier. 


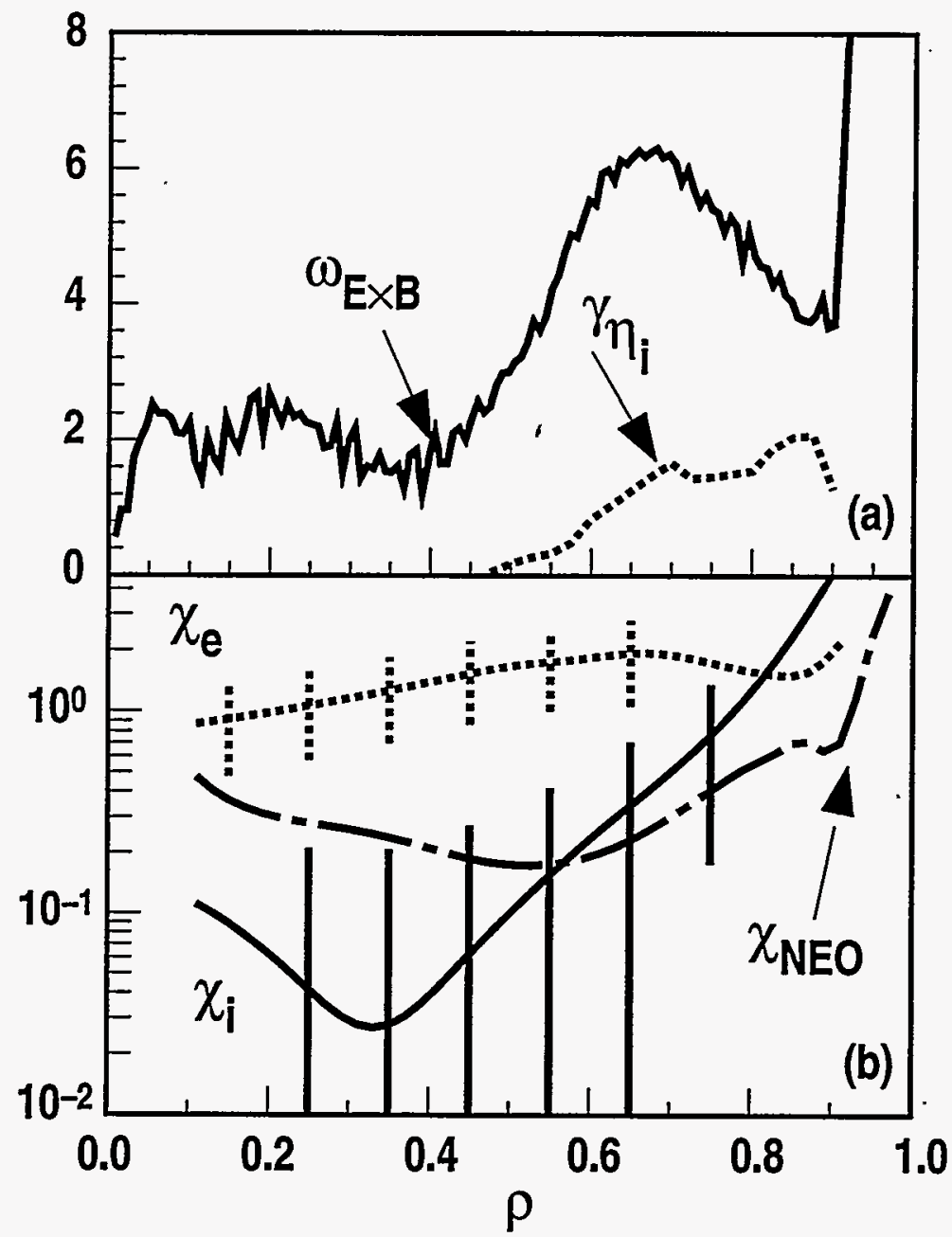

Fig. 19. The ion thermal diffusivity is at or below the standard neoclassical value across the whole minor radius of this discharge. (a) comparison of EXB shearing rate and linear growth rate showing shearing rate significantly exceeding growth rate across the whole minor radius. (b) comparison of inferred electron and ion thermal diffusivities with the Chang-Hinton neoclassical value. Results are from Ref. [6]. 


\section{SUGGESTIONS FOR FUTURE WORK}

The results discussed in this paper show that the fusion plasma physics community has made significant strides in the past decade in its ability to control plasma turbulence and reduce turbulent transport. Although we have achieved a significant level of theoretical understanding of the ExB velocity shear decorrelation mechanism, there is still a considerable amount to do to make that understanding quantitative and predictive.

If one wishes to consider linear stability, the data in Fig. 18 and the initial theoretical results 18 indicate a need for more exact predictions of the actual stabilization conditions required for the EXB shear to reduce the turbulence and transport. Theory and experiment show factors of 2 to 3 deviation from the simple rule of thumb $\omega_{\mathrm{E} \times \mathrm{B}}=$ $\gamma_{\text {MAX }}$. A fundamental problem here is that inclusion of the E $\times B$ shearing rate directly in the stability codes requires a major reformulation of the underlying model. However, given the experimental success in this area in reducing turbulence and transport, a significant effort to improve the theory is appropriate.

The more fundamental point is that the plasma usually starts in a highly turbulent state and then, if the $\mathrm{E} \times \mathrm{B}$ shearing rate is large enough, moves towards a state with reduced turbulence and transport. Accordingly, the more fundamental comparison is between $\omega_{\mathrm{E} \times \mathrm{B}}$ and $\Delta \omega_{\mathrm{D}}$. This means that, in order to understand the fundamental physics of ExB shear stabilization, we really need to understand the parametric dependence of $\Delta \omega \mathrm{D}$. Indeed, it is somewhat surprising that the comparison of $\omega_{\mathrm{E} \times \mathrm{B}}$ with $\gamma_{\text {MAX }}$ is as good as it is, since $\gamma_{\text {MAX }}$ only contains information on linear stability. 
The differing observations of changes in the electron thermal transport motivate further experimental work to isolate the factors which permit this improvement in some machines but not in others. This work would benefit from theoretical suggestions about which factors are important.

Since we are now seeing ion thermal and particle diffusivities at or below the standard neoclassical values, it is clear that the neoclassical theory of cross-field transport is finally relevant to fusion plasmas. In order to understand the cases where transport is apparently below the minimum, collisional level, there is a clear need to improve the neoclassical theory. This theory has never been properly derived for the very core of tokamak plasmas, where the size of the banana orbits is bigger than the distance to the magnetic axis. In addition, density and temperature gradient scale lengths in $\mathrm{H}$-mode edge barriers and in core transport barriers are comparable to the poloidal gyroradius. Since the analytical version of the theory was derived under the assumption that poloidal gyroradii were much smaller than the scale lengths, we need to improve the derivation of the theory to relax this assumption. Finally, it is possible that orbit squeezing effects due to the shear in $E_{\mathbf{r}} 151,152$ could also be affecting the transport.

As always, improved comparisons between theory and experiment require improved plasma diagnostics. For example, in the H-mode edge area, some theories of the transition (e.g. fluctuation-driven Reynold's stress ${ }^{153}$ ) have still not been tested some four years after their original suggestion, because of a lack of diagnostic capability. There are potential techniques using Langmuir probes in this area; however, the actual development has yet to start. Another example is the need for more direct measurements of $E_{\mathrm{r}}$, both in the plasma edge and the core to see if there are any turbulence effects. The recent realization that the motional Stark effect measurements ${ }^{126-129}$ are directly sensitive to $E_{\mathrm{r}} 154,155$ provides a possible avenue to attack this problem. Furthermore, 
the field in general would benefit from techniques to directly measure the fluctuationdriven heat and particle fluxes in the core of hot plasmas. (The Langmuir probe techniques employed at the edge are not suitable for the high temperatures in the core.) Finally, the understanding of turbulence in neutral fluids has advanced greatly with the advent of techniques to directly visualize the two dimensional turbulent fluctuations. Since the fusion plasma community now has direct ways of altering turbulence, development of such techniques for plasmas could fuel even greater progress.

Most of the work that has been done to date developing improved core confinement in tokamaks has been done with techniques that are transient. The field in general needs to move in the direction of means of producing and controlling the $\mathrm{E} \times \mathrm{B}$ shear that can be used in steady state situations. A particular need in this area is to develop techniques which can be used in a fusion power plant. 


\section{CONCLUSIONS}

The ExB shear decorrelation model has the universality needed to explain the turbulence reduction and confinement improvement seen under a number of conditions: 1) H-mode edge confinement improvement seen in limiter and divertor tokamaks, stellarators, torsatrons and mirror machines produced with a variety of heating and plasma biasing schemes; 2) the confinement improvement in the outer half of the plasma seen in $\mathrm{VH}$-mode and high internal inductance discharges and 3) the formation of core transport barriers in a number of tokamaks. In addition, there is significant qualitative agreement between theory and experiment. For example, there are spatial and temporal correlations between the changes in the EXB velocity shear, turbulence and transport reduction in both the $\mathrm{H}$-mode edge and in the plasma core. This spatial correlation is even manifested in the poloidal variation of EXB shear and turbulence seen in Fig. 13. Furthermore, there is quantitative agreement between theory and experiment. Both in the $\mathrm{H}$-mode edge and in the plasma core, the ExB shearing rate is large enough according to theory to be affecting the turbulence. Finally, there have been a number of tests of causality over the past several years; the results are consistent with the EXB velocity shear causing the reduction in turbulence and transport. In the $\mathrm{H}$-mode edge, the $\mathrm{E} \times \mathrm{B}$ shear changes prior to the change in turbulence and transport in spontaneous transitions in DIII-D. Directly altering the E $\times \mathrm{B}$ shear at the plasma edge alters turbulence and transport even prior to the radial current bifurcation in TEXTOR. Directly changing the EXB shear in the $\mathrm{VH}$-mode and elongation ramp, high $\ell_{\mathrm{i}}$ discharges with magnetic braking changes the turbulence and transport in DIII-D. The postlude ERS experiments in TFTR also demonstrate that direct changes of $E_{\mathrm{r}}$ at otherwise constant plasma parameters change turbulence and transport. 
As has been mentioned several times in this paper, there are synergistic effects between $E \times B$ velocity shear and magnetic shear. Equations (2) and (3) show that both can play a role in determining the value of $\omega_{\mathrm{E} \times \mathrm{B}}$. In addition, magnetic shear can stabilize the Kelvin-Helmholtz modes which might otherwise be driven by ExB velocity shear. Finally, negative central magnetic shear facilitates the core transport barrier formation.

Looking over the $\mathrm{E} \times \mathrm{B}$ shear effects on turbulence and transport in various parts of the plasma, it is clear that the fusion community has entered a new era in plasma confinement. We now have the ability to control turbulence and reduce turbulencedriven transport substantially. In many ways, this amounts to a revolution in our ability to confine energy in a hot, fusion-grade plasma. This achievement is particularly surprising because many of the techniques used to provoke the formation of the transport barriers (e.g. extra heat input) are ones that provide extra free energy to the plasma. In general, the greater the free energy source, the worse the turbulence gets. However, in the case of a magnetized plasma, the $\mathrm{E} \times \mathrm{B}$ velocity shear provides a mechanism for the plasma to self-organize itself into a state with reduced turbulence and transport. This is a very fundamental result in fluid dynamics. How this revolution in confinement will ultimately affect fusion as an energy source for the future remains to be seen. 


\section{REFERENCES}

${ }^{1}$ K.H. Burrell, Plasma Phys. and Controlled Fusion 36, A291 (1994).

${ }^{2}$ C.M. Greenfield, B. Balet, K.H. Burrell, M.S. Chu, J.G. Cordey, J.C. DeBoo, N. Deliyanakis, E.J. Doyle, R.J. Groebner, G.L. Jackson, S. Konoshima, D.P. O'Brien, L. Porte, C.L. Rettig, T.H. Osborne, H. St. John, A.C.C. Sips, G.M. Staebler, E.J. Strait, P.M. Stubberfield, T.S. Taylor, S.J. Thompson, K. Thomsen, A.D. Turnbull, and The JET and DIII-D Teams, Plasma Phys. and Controlled Fusion 35, B263 (1993).

${ }^{3}$ R.J. La Haye, T.H. Osborne, C.L. Rettig, C.M. Greenfield, A.W. Hyatt, J.T. Scoville, Nucl. Fusion 35, 988 (1995).

${ }^{4}$ K.H. Burrell, M.E. Austin, T.N. Carlstrom, S. Coda, E.J. Doyle, P. Gohil, R.J. Groebner, J. Kim, R.J. La Haye, L.L. Lao, J. Lohr, R.A. Moyer, T.H. Osborne, W.A. Peebles, C.L. Rettig, T.L. Rhodes, D.M. Thomas, Plasma Phys and Controlled Nucl. Fusion Research 1994 (International Atomic Energy Agency, Vienna, 1995). Vol. 1, p. 221.

5E.J. Strait, L.L. Lao, M.E. Mauel, B.W. Rice, T.S. Taylor, K.H. Burrell, M.S. Chu, E.A. Lazarus, T.H. Osborne, S.J. Thompson, and A.D. Turnbull, Phys. Rev. Lett. 75, 4421 (1995).

${ }^{6}$ L.L. Lao, K.H. Burrell, T.S. Casper, V.S. Chan, M.S. Chu, J.C. DeBoo, E.J. Doyle, R.D. Durst, C.B. Forest, C.M. Greenfield, R.J. Groebner, F.L. Hinton, Y. Kawano, E.A. Lazarus, Y.R. Lin-Liu, M.E. Mauel, W.H. Meyer, R.L. Miller, G.A. Navratil, T.H. Osborne, Q. Peng, C.L. Rettig, G. Rewoldt, T.L. Rhodes, B.W. Rice, D.P. Schissel, B.W. Stallard, E.J. Strait, W.M. Tang, T.S. Taylor, A.D. Turnbull, R.E. Waltz, and the DIII-D Team, Phys. Plasmas 3, 1951 (1996). 
7E. Mazzucato, S.H. Batha, M. Beer, R.E. Bell, R.V. Budny, C. Bush, T.S. Hahm, G.W. Hammett, F.M. Levinton, R. Nazikian, H. Park, G. Rewoldt, G.L. Schmidt, E.J. Synakowski, W.M. Tang, G. Taylor, and M.C. Zarnstorff, Phys. Rev. Lett. 77, 3145 (1996).

8H. Kimura and The JT-60 Team, Phys. Plasmas 3, 1943 (1996).

9J.L. Luxon, R. Anderson, F. Batty, C.B. Baxi, G. Bramson, N.H. Brooks, B. Brown, B. Burley, K.H. Burrell, R. Callis, G. Campbell, T.N. Carlstrom, A.P. Colleraine, J. Cummings, L. Davis, J.C. DeBoo, S. Ejima, R. Evanko, H. Fukumoto, R. Gallix, J. Gilleland, T. Glad, P. Gohil, A. Gootgeld, R.J. Groebner, S. Hanai, J. Haskovec, E. Heckman, M. Heiberger, F.J. Helton, N. Hosogane, C.-L. Hsieh, G.L Jackson, G. Jahns, G. Janeschitz, E. Johnson, A.G. Kellman, J.S. Kim, J. Kohli, A. Langhorn, L.L. Lao, P. Lee, S. Lightner, J. Lohr, M.A. Mahdavi, A. Nerem, P. Noll, T. Ohkawa, N. Ohyabu, T.H. Osborne, D.O. Overskei, P.I. Petersen, T.W. Petrie, J. Phillips, R. Prater, J. Rawls, E.E. Reis, D. Remsen, P. Riedy, P. Rock, K. Schaubel, D.P. Schissel, J.T. Scoville, R. Seraydarian, M. Shimada, T. Shoji, B. Sleaford, J.P. Smith, Jr., P. Smith, T. Smith, R.T. Snider, R.D. Stambaugh, R. Stav, H. St. John, R.E. Stockdale, E.J. Strait, R. Street, T.S. Taylor, J. Tooker, M. Tupper, S.K. Wong, S. Yamaguchi, Plasma Phys and Controlled Nucl. Fusion Research 1986 (International Atomic Energy Agency, Vienna, 1987), Vol. I, p. 159.

10N. Ninomiya and the JT-60 Team, Phys. Fluids B 4, 2070 (1992); N. Hosogane, ibid. 5, 2412 (1993); T. Kondoh and the JT-60 Team, Phys. Plasmas 1, 1489 (1994); T. Fukuda and the JT-60 Team, ibid. 2, 2249 (1995).

11E.A. Lazarus, G.A. Navratil, C.M. Greenfield, E.J. Strait, M.E. Austin, K.H. Burrell, T.A. Casper, D.R. Baker, J.C. DeBoo, E.J. Doyle, R. Durst, J.R. Ferron, C.B. Forest, P. Gohil, R.J. Groebner, W.W. Heidbrink, R.-M. Hong, W.A. Houlberg, A.W. Howald, C.-L. Hsieh, A.W. Hyatt, G.L. Jackson, J. Kim, L.L. Lao, C.J. Lasnier, A.W. Leonard, J. Lohr, R.J. La Haye, R. Maingi, R.L. Miller, M. Murakami, T.H. Osborne, 
L.J. Perkins, C.C. Petty, C.L. Rettig, T.L. Rhodes, B.W. Rice; S.A. Sabbagh, D.P.

Schissel, J.T. Scoville, R.T. Snider, G.M. Staebler, B.W. Stallard, R.D. Stambaugh, H.E. St.John, R.E. Stockdale, P.L. Taylor, D.M. Thomas, A.D. Turnbull, M.R. Wade, R. Wood, and D. Whyte, Phys. Rev. Lett. 77, 2714 (1996).

${ }^{12} \mathrm{~K}$. Ushigusa and the JT-60 Team, "Steady State Operation Research in JT-60U," Plasma Phys. and Controlled Nucl. Fusion Research 1996 (International Atomic Energy Agency, Vienna, 1997), to be published.

${ }^{13}$ T. Chiueh, $\mathrm{PhD}$. Thesis, University of Texas (1985).

14H. Biglari, P.H. Diamond and P.W. Terry, Phys. Fluids B 2, 1 (1990).

15K.C. Shaing, E.C. Crume, Jr., and W.A. Houlberg, Phys. Fluids B 2, 1492 (1990).

16Y.Z. Zhang and S.M. Mahatan, Phys. Fluids B 4, 1385 (1992).

17K. Itoh and S.-I. Itoh, Phys. Plasmas Controlled Fusion 38, 1 (1996).

17Y.Z. Zhang and S.M. Mahatan, Phys. Fluids B 4, 1385 (1992).

18R.E Waltz, G.D. Kerbel, J. Milovich, and G.W. Hammett, Phys. Plasmas 2, 2408 (1995).

${ }^{19}$ A.B. Hassam, Comments Plasma Phys. Controlled Fusion 14, 275 (1991).

${ }^{20}$ G.M. Staebler, R.R. Dominguez, Nucl. Fusion 31, 1891 (1991).

21X.-H. Wang, P.H. Diamond, and M.N. Rosenbluth, Phys. Fluids B 4, 2402 (1992).

22B.A. Carreras, K. Sidikman, P.H. Diamond, P.W. Terry and L. Garcia, Phys. Fluids B 4, 3115 (1992).

${ }^{23}$ R.R. Dominguez and G.M. Staebler, Phys. Fluids B 5, 3876 (1993).

${ }^{24}$ S. Bernabai, R. Bell, M. Chance, T.K. Chu, M. Coneliussen, W. Davis, G. Gettlefinger, T. Fibney, N. Greenough, R. Hatcher, H. Hermann, D. Ignat, S. Jardin, R. Kaita, S. Kaye, C. Kessel, T. Koaub, H. Kugel, L. Lagin, B. LeBlanc, J. Manickam, M. Okabayshi, H. Oliver, M. Ono, S. Paul, S. Preische, P. Roney, N. Sauthoff, S. Schweitzer, S. Sesnic, Y. Sun, H. Takahashi, W. Tighe, E. Valeo, S. von Goeler, K. Voss, M.E. Mauel, G.A. Navratil, R. Cesario, S. Batha, 
F. Levinton, F. Rimini, N. Asakura, S. Jones, J. Kesner, S. Luckhardt, F. Paoletti, P. Woskow, A. Zolfaghari, T. Seki, J. Bell, J. Dunlap, A. England, D. Greenwood, J. Harris, G. Henkel, S. Hirshman, R. Isler, D. Lee, L. Blush, R. Conn, R. Doerner, Y. Hirooka, R. Lehmer, L. Schmitz and G. Tynan, Phys. Fluids B 5, 2562 (1993).

25J.C.R. Hunt, D.J. Carruthers and J.C.H. Fung, in New Perspectives in Turbulence (Springer Verlag, New York, 1991), p. 55.

26B.D. Scott, P.W. Terry, and P.H. Diamond, Phys. Fluids 31, 1481 (1988).

${ }^{27}$ P.H. Diamond, V.B. Lebedev, D.E. Newman, B.A. Carreras, T.S. Hahm, W.M. Tang, G. Rewoldt, K. Avinash, "On the Transition to Enhanced Confinement in Reversed Magnetic Shear Discharges," Phys. Rev. Lett. 78 (to be published).

28V.B. Lebedev, P.H. Diamond, M.B.Isichenko, P.N. Yushmanov, D.E. Newman, B.A. Carreras, V.E. Lynch, T.S. Hahm, W.M. Tang, G. Rewoldt, K. Avinash, and A.Smolyakov, "Developments in the Theory of Core and Edge Plasma Transport Barrier Dynamics and Control," Plasma Phys. and Controlled Nucl. Fusion Research 1996 (International Atomic Energy Agency, Vienna, 1997) (to be published).

${ }^{29}$ F.L. Hinton and G.M. Staebler, Phys. Fluids B 5, 1281 (1993).

${ }^{30}$ G.M. Staebler and F.L. Hinton, Phys. Plasmas 1, 909 (1994).

31L.L. Lao, J.R. Ferron, T.S. Taylor, K.H. Burrell, V.S. Chan, M.S. Chu, J.C. DeBoo, E.J. Doyle, C.M. Greenfield, R.J. Groebner, R.A. James, E.A. Lazarus, T.H. Osborne, H. St.John, E.J. Strait, S.J. Thompson, A.D. Turnbull, D. Wroblewski, H. Zohm, and The DIII-D Team, Phys. Rev. Lett 70, 3435 (1993).

32B.A. Carreras, private communication (1996).

33R.E. Waltz, G.D. Kerbel and J. Milovich, Phys. Plasmas 1, 2229 (1994).

${ }^{34} \mathrm{M}$. Artun, $\mathrm{PhD}$. Thesis, Princeton University (1995).

35L.A. Charlton, B.A. Carreras, V.E. Lynch, and K.L. Sidikman, Phys. Plasmas 1, 2700 (1994).

36Y.B. Kim, P.H. Diamond, H. Biglari and J.D. Callen, Phys. Fluids B 3, 384 (1991). 
37Ch.P. Ritz, H. Lin, T.L. Rhodes, and A.J. Wootton, Phys. Rev. Lett. 65, 2543 (1990).

38Y.J. Kim, K.W. Gentle, Ch. P. Ritz, T.L. Rhodes, and R.D. Bengston, Phys. Fluids B 3, 674 (1991).

${ }^{39}$ R.J. Groebner, K.H. Burrell and R.P. Seraydarian, Phys. Rev. Lett. 64, 3015 (1990).

40K. Ida, S. Hidekuma, Y. Miura, T. Fujita, M. Mori, K. Hoshino, N. Suzuki, T. Yamauchi, and JFT2-M Group, Phys. Rev. Lett. 65, 1364 (1990).

41J. Kim, K.H. Burrell, P. Gohil, R.J: Groebner, Y.B. Kim, H.E. St.John, R.P. Seraydarian, and M.R. Wade, Phys. Rev. Lett. 72, 2199 (1994).

${ }^{42}$ A.C. Or and F.H. Busse, J. Fluid Mech. 174, 313 (1987).

${ }^{43}$ M.A. Azouni, E.W. Bolton and F.H. Busse, Geophys. Astrophys. Fluid Dyn. 34, 301 (1986).

44J.G. Charney and J.G. DeVore, J. Atmosph. Science 36, 1205 (1979).

${ }^{45}$ S. Chandrasekhar, Hydrodynamic and Hydromagnetic Stability (Dover, New York, 1981).

46T.S. Hahm and K.H. Burrell, Phys. Plasmas 2, 1648 (1995).

47S.E. Parker, W.W. Lee and R.A. Santore, Phys. Rev. Lett. 71, 2042 (1993).

48M. Beer, PhD. Thesis, Princeton University (1995).

${ }^{49}$ R.J. Fonck, N. Bretz, G. Cosby, R. Durst, E. Mazzucato, R. Nazikian, S. Paul, S. Scott, W. Tang and M. Zarnstorff, Plasma Phys. Contr. Fusion 34, 1993 (1992).

50K.C. Shaing, Phys. Fluids B 5, 2122 (1993).

51T.S. Hahm, Phys. Plasmas 1, 2940 (1994).

52G. Rewoldt, W.M. Tang, R.J. Hastie, Phys. Fluids 30, 897 (1987).

53M. Kotschenreuther, Bull. Am Phys. Soc. 37, 1432 (1992).

54M. Kotschenreuther, G. Rewoldt, W.M. Tang, Comput. Phys. Commun. 88, 128 (1995).

55M.A. Beer and G.W. Hammett, "Bounce Averaged Trapped Electron Fluid Equations for Plasma Turbulence," Phys. Plasmas (1996) (to be published). 
56P.H. Diamond, V. Shapiro, V. Shevchenko, Y.-B. Kim, M.N. Rosenbluth, B.A. Carreras, K. Sidikman, V.E. Lynch, L. Garcia, P.W. Terry, R.Z. Sagdeev, Plasma Phys. Controlled Nucl. Fusion Research 1992 (International Atomic Energy Agency, Vienna, 1993) Vol. 2, p. 97.

57K.L. Sidikman, B.A. Carreras, P.H. Diamond, and L. Garcia, Phys. Plasmas 1, 1142 (1994).

58S. Sen and A. Sen, Phys. Plasmas 3, 2224 (1996).

${ }^{59}$ F. Wagner, G. Becker, K. Behringer, D. Campbell, A. Eberhagen, W. Engelhardt, G. Fussmann, O. Gehre, J. Gernhardt, G. v. Gierke, G. Haas, M. Huang, F. Karger, M. Keilhacker, O. Klueber, M. Kornherr, K. Lackner, G. Lisitano, G.G. Lister, H.M. Mayer, D. Meisel, E.R. Mueller, H. Murmann, H. Niedermeyer, W. Poschenrieder, H. Rapp, H. Rohr, F. Schneider, G. Siller, E. Speth, A. Staebler, K.H. Steuer, G. Venus, O. Vollmer, and Z. Yue, Phys. Rev. Lett. 49, 1408 (1982).

${ }^{60}$ H. Matsumoto, A. Funahashi, M. Hasegawa, K. Hoshino, S. Kasai, H. Kawashima, T. Kawakami, T. Matoba, T. Matsuda, Y. Miura, M. Mori, K. Odajima, H. Ogawa, T. Ogawa, H. Ohtsuka, S. Sengoku, T. Shoji, N. Suzuki, H. Tamai, Y. Uesugi, T. Yamauchi, T. Yamamoto, A. Honda, I. Ishibori, Y. Kashiwa, M. Kazawa, K. Kukuchi, Y. Matsuzaki, K. Ohuchi, H. Okano, E. Sato, T. shibuya, T Shiina, K. Suzuki, T. Tani and K. Yokoyama, Proc. 14th European Conf. on Controlled Fusion and Plasma Heating, Madrid, Spain (European Physical Society, Petit-Lancy, Switzerland, 1987) Vol. 11D, p. 5.

61K. Toi, K. Adati, R. Akiyama, A. Ando, R. Ando, T. Aoki, D.G. Bi, J. Fujita, Y. Hamada, S. Hidekuma, S. Hirokura, K. Ida, H. Ikegami, K. Kadota, E. Kako, O. Kaneko, A. Karita, K. Kawahata, T. Kawamoto, Y. Kawasumi, S. Kitagawa, M. Kojima, S. Kubo, R. Kumazawa, T. Kuroda, K. Masai, K. Matsuura, A. Mohri, S. Morita, K. Narihara, A. Nishizawa, Y. Ogawa, K Ohkubo, Y. Oka, S. Okajima, S. Okamura, T. Ozaki, A. Sagara, M. Sakamota, M. Sasao, K. Sato, K.N. Sato, 
T. Sato, T. Seki, F. Shimpo, S. Tanahashi, Y. Taniguchi, T.Tsuzuki, T. Watari, and

H. Yamada, Proc. 16th European Conf. on Controlled Fusion and Plasma Heating,

Venice, Italy (European Physical Society, Petit-Lancy, Switzerland 1988) Vol. 13B

Part I, p. 221.

${ }^{62}$ K.H. Burrell, S.L. Allen, G. Bramson, N.H. Brooks, R.W. Callis, T.N. Carlstrom, M.S. Chu, A.P. Colleraine, D. Content, J.C. DeBoo, R.R. Dominquez, J.R. Ferron, R.L. Freeman, P. Gohil, C.M. Greenfield, R.J. Groebner, G. Haas, W.W. Heidbrink, D.N. Hill, F.L. Hinton, R.-M. Hong, W. Howl, C.L. Hsieh, G.L. Jackson, G.L. Jahns, R.A. James, A.G. Kellman, J. Kim, L.L. Lao, E.A. Lazarus, T. Lehecka, J. Lister, J. Lohr, T.C. Luce, J.L. Luxon, M.A. Mahdavi, H. Matsumoto, M. Mayberry, C.P. Moeller, Y. Neyatani, T. Ohkawa, N. Ohyabu, T. Okazaki, T.H. Osborne, D.O. Overski, T.T. Ozeki, A. Peebles, S. Perkins, M. Perry, P.I. Petersen, T.W. Petrie, R. Philipona, J.C. Phillips, R. Pinsker, P.A. Politzer, G.D. Porter, R. Prater, M.E. Rensink, M.J. Schaffer, D.P. Schissel, J.T. Scoville, R.P. Seraydarian, M. Shimada, T.C. Simonen, R.T. Snider, G.M. Staebler, B.W. Stallard, R.D. Stambaugh, R.D. Stav, H. St. John, R.E. Stockdale, E.J. Strait, P.L. Taylor, T.S. Taylor, P.K. Trost, U. Stroth, R.E. Waltz, S.M. Wolfe, R.D. Wood, and D. Wròblewski, Plasma Phys. Contr. Fusion 31, 1649 (1989).

${ }^{63}$ C.E. Bush, R.J. Goldston, S.D. Scott, E.D. Fredrickson, K. McGuire, J. Schivell, G. Taylor, C.W. Barnes, M.G. Bell, R.L. Boivin, N. Bretz, R.V. Budny, A. Cavallo, P.C. Efthimion, B. Grek, R. Hawryluk, K. Hill, R.A. Hulse, A. Janos, D.W. Johnson, S. Kilpatrick, D.M. Manos, D.K. Mansfield, D.M. Meade, H. Park, A.T. Ramsey, B. Stratton, E.J. Synakowski, H.H. Towner, R.M. Wieland, M.C. Zarnstorff, and S. Zweben, Phys. Rev. Lett. 65, 424 (1990).

${ }^{64}$ V. Erckmann, R. Brakel, R. Burhenn, P. Grigull, H.J. Hartfuss, J.V. Hoffmann, R. Jaenicke, H. Maassberg, H. Neidermeyer, W. Ohlendorf, H. Ringler, A. Rudyj, F. Wagner, A. Weller, W7-AS Team, J. Baldsuhn, B. Bomba, G. Cattanei, A. Dodhy, 
D. Dorst, A. Elsner, M. Endler, K. Engelhardt, U. Gasparino, S. Geissler, T. Geist, L. Giannone, H. Hacker, O. Heinrich, G. Herre, D. Hildebrandt, F. Karger, M. Kick, H. Froiss, s. Kubo, G. Kuehner, A. Lazaros, C. Mahn, K. McCormick, P. Pech, R. Ruhs, J. Saffert, F. Sardel, S. Sattler, F. Schneider, U. Schneider, G. Siller, U. Stroth, M. Tutter, E. Unger, U. Wenzel, H. Wolff, W. Eursching, D. Zimmermann, M. Zippe, S. Kopfel, W. Kasparek, G.A. Muller, P.G. Schuller, A.A. Borschegovskij, V.I. Il'in, I.N. Roj, V.I. Hiznyak, A.N. Kuftin, V.I. Malygin, V.E. Zapevalov, S.D. Bogdanov, V.I. Kurbatov, S.A. Malygin, V.B. Orlov, Plasma Phys. and Controlled Fusion Research 1992 (International Atomic Energy Agency, Vienna, 1993) Vol II, p. 469

65V. Erckmann, F. Wagner, J. Baldzuhn, R. Brakel, R. Burhenn, U. Gasparino, P. Grigull, H.J. Hartfuss, J.V. Hoffmann, R. Jaenicke, H. Nedermeyer, W. Ohlendorf, A. Rudyj, A. Weller, S.D. Bogdanov, B. Bomba, A.A. Borschegovsky, G. Cattanei, A. Dodhy, D. Dorst, A. Elsner, M. Endler, T. Geist, L. Giannone, H. Hacker, O. Heinrich, G. Herre, D. Hildebrandt, V.I. Hiznyak, V.I. Il'in, W. Kasparek, F. Karger, M. Kick, S. Kubo, A.N. Kuftin, V.I. Kurbatov, A. Lazaros, S.A. Malygin, V.I. Malygin, K. McCormick, G.A. Muller, V.B. Orlov, P. Pech, H. Ringler, I.N. Roi, F. Sardei, S. Sattler, F. Schneider, U. Schneider, P.G. Schuller, G. Siller, U. Stroth, M. Tutter, E. Unger, H. Wolff, E. Wursching, and S. Zopfel, Phys. Rev. Lett. 70, 2086 (1993).

66K. Toi, S. Okamura, H. Iguchi, H. Yamada, S. Morita, S. Sakakibara, K. Ida, K. Nishimura, K. Matsuoka, R. Akiyama, H. Arimoto, M. Fujiwara, M. Hosokawa, H. Idei, O. Kaneko, S. Kubo, A. Sagara, C. Takahashi, Y. Takeiri, T. Takita, K. Tsumori, I. Yamada, H. Zushi, Plasma Phys. and Controlled Nucl. Fusion Research 1992 (International Atomic Energy Agency, Vienna, 1993) Vol II, p. 461.

${ }^{67}$ K. Toi, R. Akiyama, H. Arimoto, A. Ejiri, K. Ida, H. Idei, H. Iguchi, O. Kaneko, K. Kawahata, A. Komori, S. Kubo, K. Matsuoka, T. Marisaki, S. Morita, 
K. Nishimura, S. Okamura, A. Sagara, S. Sakakibara, C. Takahashi, Y. Takita, K. Tanaka, K. Tsumori, J. Xu, H. Yamada, I. Yamada, Plasma Phys. Contr. Fusion 36, A117 (1994).

68O. Sakai, Y. Yasaka and R. Itatani Phys. Rev. Lett. 26, 4071 (1993).

${ }^{69}$ O. Sakai, K. Noda, Y. Ohe, and Y. Yasaka, Trans. Fusion Tech. 27, 417 (1995).

70J. Lohr, B.W. Stallard, R. Prater, R.T. Snider, K.H. Burrell, R.J. Groebner, D.N. Hill, K. Matsuda, C.P. Moeller, T.W. Petrie, H. St.John, and T.S. Taylor, Phys. Rev. Lett. 60, 2630 (1988).

${ }^{71}$ K. Hoshino, T. Yamamoto, H. Kawashima, N. Suzuki, Y. Uesugi, M. Mori, H. Aikawa, S. Kasai, T. Kawakami, T. Matsuda, Y. Miura, K. Odajima, H. Ogawa, T. Ogawa, H. Ohtsuka, T. Shoji, H. Tamai, T. Yamauchi, T. Kondo, I. Nakazawa, C.R. Neufeld and H. Maeda, Phys. Rev. Lett. 63, 770 (1989).

${ }^{72}$ K. Steinmetz, J.-M. Noterdaeme, F. Wagner, F. Wesner, J. Baumler, B. Becker, H.S. Bosch, M. Brambilla, F. Braun, H. Brocken, A. Eberhagen, R. Fritsch, G. Fussmann, O. Gehre, J. Gernhardt, G. v. Gierke, E. Glock, O. Gruber, G. Haas, J. Hofmann, F. Hofmeister, A. Izvozchikov, G. Janeschitz, F. Karger, M. Keilhacker, O. Kluber, M. Kornherr, K. Lackner, G. Lisitano, E. van Mark, F. Mast, H.M. Mayer, K. McCormick, D. Meisel, V. Mertens, E.R. Muller, H. Murmann, H. Neidermeyer, W. Poschenrieder, S. Puri, H. Rapp, H. Rohr, F. Ryter, K.-H. Schmitter, F. Schneider, C. Setzensack, G. Siller, P. Smeulders, F. Soldner, E. Speth, K.-H. Steuer, O. Vollmer, H. Wedler, and D. Zasche, Phys. Rev. Lett. 58, 124 (1987)

${ }^{73}$ S. Tsuji, K. Ushigusa, Y. Ikeda, T. Imai, T. Itami, M. Nemoto, K. Nagashima, Y. Koide, Y. Kawano, T. Fukuda, T. Kondoh, M. Shimada, H. Nakamura, O. Naito, H. Yoshida, T. Hioshitani, H. Kubo, K. Tobita, Y. Kusama, s. Ishida, M. Sato, N. Isei, T. Sugie, N. Miya, R. Yoshina, K. Uehara, and JT-60 Team, Phys. Rev. Lett. 64, 1023 (1990). 
74T.H. Osborne, N.H. Brooks, K.H. Burrell, T.N. Carlstrom, R.J. Groebner, W. Howl, A.G. Kellman, L.L. Lao, T.S. Taylor, D.N. Hill, N. Ohyabu, M.E. Perry, Nucl. Fusion 30, 2023 (1990).

75L.G. Ashkinazi, V.E. Golant, S.V. Lebedev, V.A. Rozhanskij, M. Tendler, Nucl. Fusion 32, 271 (1992).

76M. Kaufmann, H.S. Bosch, A. Field, G. Fussmann, O. Gruber, A. Herrmann, W. Junker, A. Kallenbach, W. Koppendorfer, K. Krieger, K. Lackner, M. Laux, V. Mertens, B. Napiontek, D. Naujoks, J. Neuhauser, W. Poschenrieder, J. Roth, F. Ryter, H. Zohm, M. Albrecht, M. Alexander, K. Asmussen, G. Becker, K. Behler, K. Behringer, A. Carlson, R. Chodura, L. Cupido, O. de Barbieri, H.J. de Blank, S. de Pena Hempel, C. Dorn, R. Drube, A. Eberhagen, W. Engelharde, J. Engstler, H.-U. Fahrbach, J.H. Feist, W. Feneberg, G. Fieg, C. Fuchs, C. Garcia-Rosales, O. Gehre, J. Gernhardt, S. gotsch, J. Gruber, K. Gunther, G. Haas, B. Heinemann, G. Herppich, W. Herrmann, F. Hofmeister, H. Hoenocker, D. Jocobi, B. Juttner, O. Kardaun, T. Kass, K Kiemer, H. Killotzek, M. Kornherr, B. Jurzan, P. Lang, R. Lang, L. Lengyel, F. Leuterer, G. Lieder, M.E. Manso, K.-F. Mast, H.-M. Mayer, P. McCarthy, D. Meisel, R. Merkel, M. Munich, H. Murmann, G. Neu, R. Neu, J.-M. Noterdaeme, G. Pautasso, C.S. Pitcher, G. Raupp, H. Richter, R. Richter, H. Rohr, N. Salmon, H. Salzmann, W. Sandmann, H.-B Schilling, M. Schittenhelm, H. Schneider, R. Schneider, W. Schneider, K. Schonmann, G. Schramm, U. Schumacher, J. Schweinzer, B. Scott, U. Seidel, R. Serra, A. Silva, F.X. Soldner, E. Speth, A. Staebler, K.-H. Steuer, B. Streibl, W. Suttrop, W. Treutterer, M. Troppmann, N. Tsois, M. Ulrich, P. Varela, G. Venus, H. Vernickel, O. Vollmer, H. Wedler, M. Weinlich, U. Wenzel, F. Wesner, R. Wilhelm, R. Wunderlich, D. Zasche, H.-P. Zehrfeld, Plasma Phys. Contr. Fusion 35, B205 (1993).

77P.G. Carolan, S.J. Fielding, S. Gerasimov, J. Hugill, A.W. Morris, D.C. Robinson, T.N. Todd, M. Valovic, J. Ashall, K.B. Axon, R.A. Bamford, C.A. Bunting, 
E. Edlington, A.M. Edwards, J.G. Ferreira, S.J. Manhood, R. O'Connel, M.A.

Singleton, K. Stammers, J. Tomas, D.L. Trottman, and the Compass-D Team, Plasma Phys. Contr. Fusion 36, A111 (1994).

78R.J. Taylor, M.L. Brown, B.D. Fried, H. Grote, J.R. Liberati, G.J. Morales, and P. Pribyl, Phys. Rev. Lett. 63, 2365 (1989).

${ }^{79}$ R.R.Weynants, D. Bora, T. Delvigne, F. Dugodie, M. Gaigneaux, B. Giesen, R.S. Ivanov, Y.T. Lie, A.M. Messiaen, R.A. Moyer, U. Samm, R.P. Schorn, B. Schweer, C. Stickelmann, G. Telesca, R. van Nieuwenhove, G. van Oost, G. van Wassenhove, P.E. Vandenplas, G.H. Wolf, J.W. Yang, Plasma Phys. and Controlled Nucl. Fusion Research 1990 (International Atomic Energy Agency, Vienna, 1991) Vol. I, p. 473. ${ }^{80}$ F. Wagner, G. Fussmann, T. Grave, M. Keilhacker, M. Kornherr, K. Lackner, K. McCormick, E.R. Mueller, A. Staelber, G. Becker, K. Bernhardi, U. Ditte, A. Eberhagen, O. Gehre, J. Gernhardt, G. v. Fierke, E. Glock, O. Gruber, G. Haas, M. Hesse, G. Janeschitz, F. Karger, S. Kissel, O. Klueber, G. Lisitano, H.M. Mayer, D. Meisel, V. Mertens, H. Murmann, W. Poschenrieder, H. Rapp, H. Roehr, F. Ryter, F. Schneider, G. Siller, P. Smeulders, F. Soeldner, E. Speth, K.-H. Steuer, Z. Szymanski, and O. Vollmer, Phys. Rev. Lett. 53, 1453 (1984).

${ }^{81}$ T. LeHecka, E.J. Doyle, R. Philipona, N.C. Luhmann,Jr., W.A. Peebles, C.L. Hsieh, T.N. Carlstrom, R.P. Seraydarian and the DIII-D Group, Proc. 16th European Conf. on Controlled Fusion and Plasma Physics, Venice, Italy, 1989\} (European Physical Society, Petit-Lancy, Switzerland) Vol. 13B, p. 123.

82E. Holzhauer, G. Dodel and the ASDEX Team, Rev. Sci. Instrum. 61, 2817 (1990). ${ }^{83}$ M.E. Manso, F. Wagner, J. Mathias, A. Silva, H. Zohm, F. Serra, R. Buchse, P. Varela, Proc. 18th European Conf. on Controlled Fusion and Plasma Physics, Berlin, Germany (European Physical Society, Petit-Lancy, Switzerland, 1991) Vol. 15C, p. 393. 
${ }^{84}$ K.H. Burrell, T.N. Carlstrom, E.J. Doyle, D. Finkenthal, P. Gohil, R.J. Groebner, D.L. Hillis, J. Kim; H. Matsumoto, R.A. Moyer, T.H. Osborne, C.L. Rettig, W.A. Peebles, T.L. Rhodes, H. St. John, R.D. Stambaugh, M.R. Wade, and J.G. Watkins, Plasma Phys. Contr. Fusion 34, 1859 (1992).

85R.J. Groebner, Phys. Fluids B 5, 2343 (1993).

86F. Wagner; J. Baldzuhn, R. Brakel, R. Burhenn, V. Erckmann, T. Estrada, P. Grigull, H.J. Hartfuss, G. Herre, M. Hirsch, J.V. Hoffmann, R. Jaenicke, A. Rudyj, U. Stroth, A. Weller and The W7-AS Teams, Plasma Phys. Contr. Fusion 36, A61 (1994).

87F. Wagner, J. Baldzuhn, V. Erckmann, Y.H. Feng, P. Grigull, J.V. Hofmann, C. Konrad, F. Sardei, R. Brakel, S. Fiedler, L. Giannone, H.J. Hartfuss, G. Herre, D. Hildebrandt, M. Hirsch, R. Jaenicke, W. Ohlendorf, P. Pech, E. Wuersching, B. Branas, E. De La Luna, S. Zoletnik, Plasma Phys. and Controlled Nucl. Fusion Research 1994 (International Atomic Energy Agency, Vienna, 1995) Vol. I, p. 559.

88F. Wagner, J. Baldzuhn, R. Brakel, B. Branas, R. Burhenn; J. Das, E. De La Luna, V. Erckmann, Y. Feng, S. Fiedler, L. Giannone, P. Grigull, H.-J. Hartfuss, O. Heinrich, G. Herre, M. Hirsch, J.V. Hofmann, E. Holzhauer, R. Jaenicke, Ch. Konrad, G. Kocsis, W. Ohlendorf, P. Pech, F. Sardei, E. Wuersching, S. Zoletnik, Trans. Fusion Tech. 27, 32 (1995).

${ }^{89}$ G.R. Tynan, L. Schmitz, L. Blush, J.A. Boedo, R.W. Conn, R. Doerner, R. Lehmer, R. Moyer, H. Kugel, R. Bell, S. Kaye, M. Okabayashi, S. Sesnic, Y. Sun and PBX-M Group, Phys. Plasmas 1, 3301 (1994).

90R.A. Moyer, K.H. Burrell, T.N. Carlstrom, S. Coda, R.W. Conn, E.J. Doyle, P. Gohil, R.J. Groebner, J. Kim, R. Lehmer, W.A. Peebles, M. Porkolab, C.L. Rettig, T.L. Rhodes, R.P. Seraydarian, R.E. Stockdale, D.M. Thomas, G.R. Tynan, and J.G. Watkins, Phys. Plasmas 2, 2397 (1995).

91G.R. Tynan, L. Schmits, R.W. Conn, R. Doerner and R. Lehmer, Phys. Rev. Lett 68, 3032 (1992). 
${ }^{92}$ G.R. Tynan, J.A. Boedo, D.S. Gray, R. van Nieuwenhove, G. Van Oost, and R.R. Weynants, J. Nuclear Mater. 196-198, 770 (1992).

93E.J. Doyle, E.J. Doyle, P. Gohil, R.J. Groebner, T. Lehecka, N.C. Luhmann, Jr., M.A. Mahdavi, T.H. Osborne, W.A. Peebles, and R. Philipona, Plasma Phys. and Controlled Nucl. Fusion Research 1992 (International Atomic Energy Agency, Vienna, 1993) Vol. I, p. 235.

94H. Matsumoto, K.H. Burrell, T.N. Carlstrom, E.J. Doyle, P. Gohil, R.J. Groebner, T. Lehecka, N.C. Luhmann, Jr., M.A. Mahdavi, T.H. Osborne, W.A. Peebles, and R. Philipona, Plasma Phys. and Controlled Fusion 34, 615 (1992).

95S. Ohdachi, T. Shoji, K. Nagashima, H. Tamai, Y. Miura, H. Maeda, H. Toyama, and JFT2-M Group, Plasma Phys. Contr. Fusion 36, A201 (1994).

96S. Coda, M. Porkolab and T.N. Carlstrom, Rev. Sci. Instrum 63, 4974 (1992).

97R. Philipona, E.J. Doyle, N.C. Luhmann, Jr., W.A. Peebles, C.L. Rettig, K.H. Burrell, R.J. Groebner, H. Matsumoto, and the DIII-D Group, Rev. Sci. Instrum. 61, 3007 (1990).

98K.H. Burrell, M.E. Austin, T.N. Carlstrom, S. Coda, E.J. Doyle, P. Gohil, R.J. Groebner, J. Kim, R.J. La Haye, L.L. Lao, J. Lohr, R.A. Moyer, T.H. Osborne, W.A. 'Peebles, C.L. Rettig, T.L. Rhodes, D.M. Thomas, Plasma Physics and Controlled Nuclear Fusion Research 1994 (International Atomic Energy Agency, Vienna, 1995), Vol. I, p. 221

${ }^{99}$ R.J. Groebner, M.E. Austin, K.H. Burrell, T.N. Carlstrom, S. Coda, E.J. Doyle, P. Gohil, J. Kim, R.J. La Haye, C.L. Hsieh, L.L. Lao, J. Lohr, R.A. Moyer, C.L. Rettig, T. Rhodes, G.M. Staebler, R.E. Stockdale, D.M. Thomas and J.G. Watkins in the AIP Conference Proceedings 345, International Conference on Plasma Physics ICPP 1994, (American Institute of Physics, Woodbury, New York, 1995), p. 74. 
100K.H. Burrell, T.N. Carlstrom, S. Coda, E.J. Doyle, P. Gohil, R.J. Groebner, J. Kim, R.A. Moyer, W.A. Peebles, C.L. Rettig, T.L. Rhodes, and D.M. Thomas, Plasma Phys. Contr. Fusion 38, 1313 (1996).

101S.Jachmich, A.Lyssoivan, G. Van Oost, R. Weynants, J. Boedo, M. Brix, A. Huber and B. Schweer, "Study of the Causality Between Radial Electric Field and Confinement Changes During Edge Polarization in TEXTOR-94," KFA-Jülich Report LPP-ERM/KMS Nr 107 (1996) submitted to Plasma Phys. Control. Fusion. ${ }^{102}$ A. Mase, J.H. Jeong, A. Itakura, K. Ishii, M. Inutake, and S. Miyoshi, Phys. Rev. Lett. 64, 2281 (1990).

${ }^{103}$ A. Mase, A. Itakura, M. Inutake, K. Ishii, J.H. Jeong, K. Hattori, and S. Miyoshi, Nucl. Fusion 31, 1725 (1991).

${ }^{104}$ G.L. Jackson, J. Winter, T.S. Taylor, K.H. Burrell, J.C. DeBoo, C.M. Greenfield, R.J. Groebner, T. Hodapp, K.L. Holtrop, E.A. Lazarus, L.L. Lao, S.I. Lippmann, T.H. Osborne, T.W. Petrie, J. Phillips, R.E. James, D.P. Schissel, E.J. Strait, A.D. Turnbull, W.P. West, and The DIII-D Team, Phys. Rev. Lett. 67, 3098 (1991). ${ }^{105}$ G.L. Jackson, J. Winter, T.S. Taylor, C.M. Greenfield, K.H. Burrell, T .N. Carlstrom, J.C. DeBoo, E.J. Doyle, R.J. Groebner, L.L. Lao, C.L. Rettig, D.P. Schissel, E.J. Strait, and The DII-D Research Team, Phys Fluids B 4, 2181 (1992).

${ }^{106}$ T.H. Osborne, K.H. Burrell, T.N. Carlstrom, M.S. Chu, J.C. DeBoo, E.J. Doyle, P. Gohil, C.M. Greenfield, R.J. Groebner, G.L. Jackson, Y.B. Kim, S. Konoshima, R.J. La Haye, L.L. Lao, S.I. Lippmann, C.L. Rettig, R.D. Stambaugh, G.M. Staebler, H. St. John, E.J. Strait, T.S. Taylor, S.J. Thompson, A.D. Turnbull, J. Winter and D. Wròblewski, Nucl. Fusion 35, 23 (1995).

${ }^{107}$ T.H. Osborne, K.H. Burrell, T.N. Carlstrom, M.S. Chu, J.C. DeBoo, E.J. Doyle, J.R. Ferron, P. Gohil, C.M. Greenfield, R.J. Groebner, A.W. Hyatt, G.L. Jackson, Y.B. Kim, S. Konoshima, T.K. Kurki-Suonio, R.J. La Haye, E.A. Lazarus, L.L. Lao, S.I. Lippmann, T.W. Petrie, C.L. Rettig, R.D. Stambaugh, G.M. Staebler, H. St. John, 
E.J. Strait, T.S. Taylor, S.J. Thompson, A.D. Turnbull, D. Wròblewski, and The DIII-D Team, Plasma Phys. Contr. Fusion 36, A237 (1994).

108JET Team, Plasma Phys. Contr. Fusion 36, A23 (1994).

${ }^{109}$ K. Thomsen, B. Balet, D.J. Campbell, C.D. Challis, J.G. Cordey, N. Deliyanakis, J.J. Ellis, C.M Greenfield, N. Hawkes, D.G. Muir, D.P. O'Brien, R. Reichle, D. Stork, P. Stubberfield, P.R. Thomas, and The JET Team, Plasma Phys. Contr. Fusion 36, A243 (1994).

110K.H. Burrell, T.H. Osborne, R.J. Groebner, and C.L. Rettig, in Proc. 20th European Conf. on Controlled Fusion and Plasma Physics (European Physical Society, PetitLancy, Switzerland, 1993), Vol. 17C, p. 27.

111 C.L. Rettig, W.A. Peebles, K.H. Burrell, R.J. La Haye, E.J. Doyle, R.J. Groebner, and N.C. Luhmann, Jr., Phys. Fluids B 5, 2428 (1993).

${ }^{112}$ C.L. Rettig, K.H. Burrell, R.J. La Haye, T.H. Osborne, W.A. Peebles, and R.J. Groebner, Plasma. Phys. Contr. Fusion 36, A207 (1994).

${ }^{113}$ R.J. La Haye, R.J. Groebner, A.W. Hyatt, J.T. Scoville, Nucl. Fusion 33, 349 (1993).

${ }^{114}$ R.J. La Haye, C.M. Greenfield, R.J. Groebner, A.W. Hyatt, L.L. Lao, T.H. Osborne, C.L. Rettig, and J.T. Scoville, in Proc. Varenna Workshop on Local Transport Studies in Fusion Plasmas, J.D. Callen, G. Gorini and E. Sindoni Eds, (Societa Italiana di Fisica), p. 283.

115K.H. Burrell, E.J. Doyle, P. Gohil, R.J. Groebner, J. Kim, R.J. La Haye, L.L. Lao, R.A. Moyer, T.H. Osborne, W.A. Peebles, C.L. Rettig, T.H. Rhodes, and D.M. Thomas, Phys. Plasmas 1, 1536 (1994).

116J.T. Scoville and R.J. La Haye, "Plasma Response in DII-D to an Externally Applied Low m, n=1 Error Field," General Atomics Report GA-A20968 (1994), submitted to Nucl. Fusion.

117JET Team, in Plasma Physics and Controlled Nuclear Fusion Research 1988 (International Atomic Energy Agency, Vienna, 1989) Vol. 1, p 215. 
${ }^{118 H}$ H. Hugon, Ph. van Milligen, P. Smeulders, L.C. Appel, D.V. Bartlett, D. Boucher, A.W. Edwards, L.-G. Erickson, C.W. Gowers, T.C. Hendler, G. Huysmans, J.J. Jacquinot, P. Kupschus, L. Porte, P.H. Rebut, D.F.J. Start, F. Tibone, B.J.D. Tubbing, M.L. Watkins, and W. Zwingmann, Nucl. Fusion 32, 33 (1992).

${ }^{119}$ E.A. Lazarus, L.L. Lao, T.H. Osborne, T.S. Taylor, A.D. Turnbull, M.S. Chu, A.G. Kellman, E.J. Strait, J.R. Ferron, R.J. Groebner, W.W. Heidbrink, T.N. Carlstrom, F.J. Helton, C.L. Hsieh, S.I. Lippmann, D.P. Schissel, R.T. Snider and D. Wròblewski, Phys. Fluids B 4, 3644 (1992).

${ }^{120}$ S. Ishida, M. Matsuoka, M. Kikuchi, S. Tsuji, T. Nishitani, Y. Koide, T. Ozeki, T. Fujita, H. Nakamura, N. Hosogane, Y. Kamada, R. Yoshino, D. Humphreys, N. Isei, M. Sato, H. Hsuan, H. Shirai, T. Hirayama, M. Azumi, H. Kubo, M. Kuriyama, M. Nemoto, H. Takeuchi, JT-60 Team, Plasma Phys. and Controlled Nucl. Fusion Research 1992 (International Atomic Energy Agency, Vienna, 1993), Vol. I, p. 219.

${ }^{121}$ S. Ishida, Y. Neyatani, Y. Kamada, A. Isayama, T. Fujita, T. Oikawa, Y. Koide, Y. Kawano, H. Shirai, T. Ozeki, T. Nishitani, S. Takeji, H. Kimura, T. Hatae, T. Fukuda, N. Isei, and the JT-60 Team, "High Performance Experiments in the JT-60U High Current Divertor Discharges," Plasma Phys. and Controlled Nucl. Fusion Research 1996 (International Atomic Energy Agency, Vienna, 1997) to be published.

${ }^{122}$ E.J. Strait, T.S. Taylor, A.D. Turnbull, J.R. Ferron, L.L. Lao, B. Rice, O. Sauter, S.J. Thompson, and D. Wròblewski, in Proc. 21st European Conf. on Controlled Fusion and Plasma Physics (European Physical Society, Petit-Lancy, Switzerland) Vol 18B, Part I, p. 242.

${ }^{123}$ E.J. Strait, T.S. Taylor, A.D. Turnbull, J.R. Ferron, L.L. Lao, B. Rice, O. Sauter, S.J. Thompson, and D. Wròblewski, Phys. Rev. Lett. 74, 2483 (1995). 
${ }^{124}$ T.S. Taylor, E.J. Strait, L.L. Lao, M. Mauel, A.D. Turnbull, K.H. Burrell, M.S. Chu, J.R. Ferron, R.J. Groebner, R.J. La Haye, B.W. Rice, R.T. Snider, S.J. Thompson, D. Wròblewski and D.J. Lightly, Phys. Plasmas 2, 2390 (1995).

${ }^{125}$ R.J. Goldston, S.H. Batha, R.H. Bulmer, D.N. Hill, A.W. Hyatt, S.C. Jardin, F.M. Levinton, S.M. Kaye, C.E. Kessel, E.A. Lazarus, J. Manickam, G.H. Neilson, W.M. Nevins, L.J. Perkins, G. Rewoldt, K.I. Thomassen, M.C. Zarnstorff, and the National TPX Physics Team, Plasma Phys. Contr. Fusion 36, B213 (1994).

126F.M. Levinton, Rev. Sci. Instrum. 63, 5157 (1992).

${ }^{127}$ B.W. Rice, D.G. Nilson, D. Wròblewski, Rev. Sci. Instrum. 66, 373 (1995).

${ }^{128}$ F.M. Levinton, R.J. Fonck, B.M. Gammel, H.W. Kugel, E.T. Powell, and D.W. Roberts, Phys. Rev. Lett. 63, 2060 (1989).

${ }^{129}$ D Wròblewski, K.H. Burrell, L.L. Lao, P. Politzer, W.P. West, Rev. Sci. Instrum. 61, 3552 (1990).

${ }^{130}$ F.M. Levinton, M.C. Zarnstorff, S.H. Batha, M. Bell, R.E. Bell, R.V. Budny, C. Bush, Z. Chang, E. Fredrickson, A. Janos, J. Manickam, A. Ramsey, S.A. Sabbagh, G.L. Schmidt, E.J. Synakowski, and G. Taylor, Phys. Rev. Lett. 75, 4417 (1995).

131 JET Team, in Plasma Physics and Controlled Nuclear Fusion Research 1994 (International Atomic Energy Agency, Vienna, 1995) Vol. I, p. 423.

132F.X. Söldner, B. Balet, Y. Baranov, A. Ekedahl, B. Fischer, J.P. Goedbloed, C. Gormezano, H.A. Holties, G.T.A. Huysmans, M. Lennholm, V.V. Parail, F. Rimini, P. Schild, A.C.C. Sips, F. Smits, E. Springmann, A. Taroni, B.J.D. Tubbing, Controlled Fusion and Plasma Physics (European Physical Society, PetitLancy, Switzerland, 1995) Vol. 19C, Part IV, p. 113.

${ }^{133}$ G.T. Hoang, G. Gil, E. Joffrin, D. Moreau, A. Becoulet, P. Bibet, J.P. Bizarro, R.V. Budny, J. Carrrasco, J.P. Coulon, C. De Michelis, T. Dudok De Wit, P. MonierGarbet, M. Goniche, R. Guirlet, T. Hutter, S.M. Kaye, J. Lasalle, L. Laurent, 
P. Lecoustey, X. Litaudon, M. Mattioli, Y. Peysson, A.-L. Pecquet, G. Rey, S.A. Sabbagh, B. Saoutic, G. Tonon, J.C. Vallet, Nucl. Fusion 34, 75 (1994).

${ }^{134}$ X. Litaudon, R. Arslanbekov, G.T. Hoang, E. Joffrin, F. Kazarian-Vibert, D. Moreau, Y. Peysson, P. Bibet, P. Froissard, M. Goniche, G. Rey, J. Ferron and K. Kupfer, Plasma Phys. Contr. Fusion 38, 1603 (1996).

${ }^{135}$ S. Ide, O. Naito, T. Fujita, T. Oikawa, M. Seki, and the JT-60 Team, "Application of LHCD for Sustainment and Control of a Reversed Magnetic Shear Plasma in JT-60U," Plasma Phys. and Controlled Nucl. Fusion Research 1996 (International Atomic Energy Agency, Vienna, 1997) to be published.

136B.W. Rice, K.H. Burrell, L.L. Lao, G. Navratil, B.W. Stallard, E.J. Strait, T.S. Taylor, M.E. Austin, T.A. Casper, M.S. Chu, C.B. Forest, P. Gohil, R.J. Groebner, W.W. Heidbrink, A.W. Hyatt, H. Ikezi, R.J. La Haye, E.A. Lazarus, Y.R. Lin-Liu, M.E. Mauel, W.H. Meyer, C.L. Rettig, D.P. Schissel, H.E. St.John, P.L. Taylor, A.D. Turnbull and the DII-D Team, Phys. Plasmas 3, 1983 (1996).

137T. Fujita, S. Ide, H. Shirai, O. Naito, Y. Koide, S. Takeji, H. Kubo, S. Ishida and M. Kikuchi, "Internal Transport Barrier for Electrons in JT-60U Reversed Shear Discharges," submitted to Phys. Rev. Lett.

${ }^{138}$ T. Fujita, S. Ide, H. Kimura, Y. Koide, T. Oikawa, S. Takeji, H. Shirai, T. Ozeki, Y. Kamada, S. Ishida and the JT-60 Team, "Enhanced Core Confinement in JT-60U Reversed Shear Discharges," Plasma Phys. and Controlled Nucl. Fusion Research 1996 (International Atomic Energy Agency, Vienna, 1997) to be published.

${ }^{139}$ E.J. Synakowski, S.H. Batha, M.A. Beer, M.G. Bell, R.E. Bell, R.V. Budny, C.E. Bush, P.C. Efthimion, G.W. Hammett, T.S. Hahm, B. LeBlanc, F. Levinton, E. Mazzucato, H. Park, A.T. Ramsey, G. Rewoldt, S.D. Scott, G. Schmidt, W.M. Tang, G. Taylor, and M.C. Zarnstorff, "The Roles of Electric Field Shear and Shafranov Shift in Sustaining High Confinement in Enhanced Reverse Shear Plasmas on the TFTR Tokamak," submitted to Phys. Rev. Lett. 
${ }^{140}$ C.M. Greenfield, D.P. Schissel, B.W. Stallard, E.A. Lazarus, G.A. Navratil, K.H. Burrell, T.A. Casper, J.C. DeBoo, E.J. Doyle, R.J. Fonck, C.B. Forest, P. Gohil, R.J. Groebner, M. Jakubowski, L.L. Lao, M. Murakami, C.C. Petty, C.L. Rettig, T.L. Rhodes, B.W. Rice, H.E. St. John, G.M. Staebler, E.J. Strait, T.S. Taylor, A.D. Turnbull, K.L. Tritz, R.E. Waltz, and The DIII-D Team, "Transport and Performance in DIII-D Discharges with Weak or Negative Central Magnetic Shear," submitted to Phys. Plasmas (this conference).

141Y. Koide and the JT-60 Team, "Progress in the JAERI Tokamak-60 Upgrade Experiments With Negative-Ion Based Neutral Beams," submitted to Phys. Plasmas (this conference).

142E.J. Doyle, K.H. Burrell, T.N. Carlstron, S. Coda, J.C. DeBoo, R.D. Durst, R.J. Fonck, P. Gohil, C.M. Greenfield, R.J. Groebner, J. Kim, K.W. Kim, R.J. La Haye, L.L. Lao, E.A. Lazarus, R.A. Moyer, G. Navratil, T.H. Osborne, W.A. Peebles, C.L. Rettig, T.L. Rhodes, B.W. Rice, D.P. Schissel, G.M. Staebler, T.S. Taylor, D.M. Thomas, E.J. Strait and R.E. Waltz, "Physics of Turbulence Control and Transport Barrier Formation in DIII-D," Plasma Phys. and Controlled Nucl. Fusion Research 1996 (International Atomic Energy Agency, Vienna, 1997) (to be published).

${ }^{143}$ E. Mazzucato, S.H. Batha, M. Beer, M.G. Bell, R.E. Bell, R.V. Budny, C.E. Bush, P.C. Efthimion, T.S. Hahm, G. Hammett, B. LeBlanc, F.M. Levinton, R. Nazikian, H. Park, S. Paul, G. Rewoldt, G. Schmidt, S.D. Scott, E.J. Synakowski, W.M. Tang, G. Taylor and M.C. Zarnstorff, "Turbulent Fluctuations in the Main Core of TFTR Plasmas with Negative Magnetic Shear," Plasma Phys. and Controlled Nucl. Fusion Research 1996 (International Atomic Energy Agency, Vienna, 1997) (to be published).

${ }^{144}$ F.M. Levinton, S.H. Batha, M. Beer, M.G. Bell, R.E. Bell, R.V. Budny, C.E. Bush, P.C. Efthimion, E. Mazzucato, R. Nazikian, H. Park, A. Ramsey, G.L. Schmidt, S.D. Scott, E.J. Synakowski, G. Taylor, S. von Goeler, and M.C. Zarnstorff, "Transport 
Physics in Reversed Shear Plasmas," Plasma`Phys. and Controlled Nucl. Fusion Research 1996 (International Atomic Energy Agency, Vienna, 1997) (to be published).

145E. Synakowski, S.H. Batha, M.A. Beer, R.E. Bell, R.V. Budny, C.E. Bush, P.C. Efthimion, T.S. Hahm, G.W. Hammett, B. LeBlanc, F. Levinton, E. Mazzucatto, H. Park, A.T. Ramsey, G. Schmidt, G. Rewoldt, S.D. Scott, G. Taylor, M.C. Zarnstorff, submitted to Phys. Plasmas (this conference).

146D.P. Schissel, C.M. Greenfield, J.C. DeBoo, L.L. Lao, E.A. Lazarus, G.A. Navratil, B.W. Rice, G.M. Staebler, B.W. Stallard, E.J. Strait, H.E. St.John, M.E. Austin, K.H. Burrell, T.A. Casper, D.R. Baker, V.S. Chan, E.J. Doyle, J.R. Ferron, C.B. Forest, P. Gohil, R.J. Groebner, W.W. Heidbrink, R.-M. Hong, A.W. Howald, C.-L. Hsieh, A.W. Hyatt, G.L. Jackson, J. Kim, C.J. Lasnier, A.W. Leonard, J. Lohr, R.J. La Haye, R. Maingi, R.L. Miller, M. Murakami, T.H. Osborne, C.C. Petty, C.L. Rettig, T.L. Rhodes, S. Sabbagh, J.T. Scoville, R.T. Snider, R.D. Stambaugh, R.E. Stockdale, P.L. Taylor, T.S. Taylor, D.M. Thomas, M.R. Wade, R.E. Waltz, R.D. Wood, and D.G. Whyte, "Local Analysis of Confinement and Transport in Neutral Beam-Heated DIII-D Discharges with Negative Magnetic Shear," Plasma Phys. and Controlled Nucl. Fusion Research 1996 (International Atomic Energy Agency, Vienna, 1997) (to be published).

147Y. Koide, S. Ishida, M. Kikuchi, M. Mori, S. Tsuji, T. Nishitani, Y. Kawano, T. Hatae, T. Fujita, T. Ozeki, H. Shirai, Y. Kamada, R. Yoshino, H. Ninomiya, M. Azumi, JT-60 Team, Plasma Phys. and Controlled Nucl. Fusion Research 1994 (International Atomic Energy Agency, Vienna, 1995) Vol. I, p. 199.

148Y. Koide, M. Kikuchi, M. Mori, S. Tsuji, S. Ishida, N. Asakura, Y. Kamada, T. Nishitani, Y. Kawano, T. Hatae, T. Fujita, T. Fukuda, A. Sakasai, T. Kondoh, R. Yoshino, and Y. Neyatani, Phys. Rev. Lett. 72, 3662 (1994). 
${ }^{149}$ Y. Koide, T. Takizuka, S. Takeji, S. Ishida, M. Kikuchi, Y. Kamada, T. Ozeki, Y. Neyatani, H. Shirai, M. Mori, and S. Tsuji-Lio, Plasma Phys. Contr. Fusion 38, 1011 (1996).

${ }^{150}$ C.B. Forest, C.C. Petty, M.E. Austin, F.W. Baity, K.H. Burrell, S.C. Chiu, M.S. Chu, J.S. DeGrassie, P. Gohil, A.W. Hyatt, H. Ikezi, E.A. Lazarus, M. Murakami, R.I. Pinsker, M. Porkolab, R. Prater, B.W. Rice, G.M. Staebler, E.J. Strait and T.S. Taylor, Phys. Rev. Lett. 77, 3141 (1996).

151R.D. Hazeltine, Phys. Fluids B 1, 2031 (1989).

152F.L. Hinton and Y.B. Kim, Phys. Plasmas 2, 159 (1995).

153B.A. Carreras, V.E. Lynch, L. Garcia, P.H. Diamond, Phys. Fluids B 5, 1491 (1993).

${ }^{154}$ B.W. Rice, K.H. Burrell, and L.L. Lao, "Effect of Plasma Radial Electric Field on Motional Stark Effect Measurements and Equilibrium Reconstruction," General Atomics Report GA-A22480 (1996), submitted to Nucl. Fusion.

155M.C. Zarnstorff, F.M. Levinton, S.H. Batha, and E.J. Synakowski, "The Effect of $E_{\mathrm{r}}$ on MSE Measurements of q, a New Technique for Measuring $E_{\mathrm{r}}$ and a Test of the Neoclassical Electric Field," submitted to Phys. Plasmas. 


\section{ACKNOWLEDGMENT}

This is a report of work supported by the U.S. Department of Energy under Contract Nos. DE-AC03-89ER51114, W-7405-ENG-48, DE-AC05-96OR22464, DE-AC0494AL85000, and Grant Nos. DE-FG02-91ER54109, DE-FG03-86ER53266, and DEFG03-95ER54294.

I would like to thank the following people for their contribution to this paper: M.E. Austin, J.A. Boedo, B.A. Carreras, S. Coda, P.H. Diamond, E.J. Doyle, R.J. Fonck, C.M. Greenfield, R.J. Groebner, T.S. Hahm, F.L. Hinton, M. Hirsh, S. Jachmich, Y. Koida, J. Kim, Y.B. Kim, L.L. Lao, R.J. La Haye, E.A. Lazarus, F.M. Levinton, J. Lohr, E. Mazzucato, R.A. Moyer, G.A. Navratil, T.H. Osborne, M. Porkolab, C.L. Rettig, G. Rewoldt, T.L. Rhodes, B.W. Rice, D.P. Schissel, J.T. Scoville, G.M. Staebler, B.W. Stallard, E.J. Synakowski, W.M. Tang, F. Wagner, R.E. Waltz, and M.C. Zarnstorff. 